INSTITUTO DE PESQUISAS ENERGÉTICAS E NUCLEARES

Autarquia Associada à Universidade de São Paulo

USO DA RADIAÇÃO GAMA DO COBALTO-60 EM ÁCAROS DE IMPORTÂNCIA AGRÍCOLA VISANDO O TRATAMENTO QUARENTENÁRIO

André Ricardo Machi

Dissertação apresentada como parte dos requisitos para obtenção do Grau de Mestre em Ciências na Área de Tecnologia Nuclear - Aplicações.

Orientador:

Prof. Dr. Valter Arthur

São Paulo

2013 
"Dedico esse trabatho aos mens Pais José Aparecido Machi e María Bernadete da Sílva Machi que sempre me ajudaram como puderam e nunca me abandonaram nos momentos de maior dificuldade". 


\section{AGRADECIMENTOS}

Agradeço a Deus por me dar força e coragem para enfrentar os desafios e ser meu guia nas horas mais difíceis. Tudo o que você faz é válido como experiência e amadurecimento pessoal.

À meu amigo e orientador, Prof. Dr. Valter Arthur pelas valiosas discussões, companheirismo e ensinamentos sobre a vida e ajuda nas horas mais difíceis, paciência e confiança no meu trabalho.

À minha namorada Fernanda Esteca por todo o carinho, paciência e compreensão e ajuda nas correções e por ser minha companheira e estar sempre comigo nas horas mais difíceis.

Agradeço muito ao amigo Thiago Ansante da Entomologia e Acarologia ESALQ/USP pela ajuda nas análises.

Ao Departamento de Entomologia e Acarologia da ESALQ/USP pelos ácaros e aos amigos do departamento.

Aos Professores e funcionários do IPEN pela ajuda e amizade.

Aos meus amigos do CRUSP e IPEN pela amizade, ajuda e também pelos bons momentos e a troca de ensinamentos durante meu curso.

À técnica do Laboratório de Radiobiologia e Ambiente Lucia Cristina Aparecida Santos Silva pela ajuda e amizade durante todo o meu Mestrado

Aos meus amigo(a)s do laboratório e também os funcionários do CENA/USP pelos ótimos momentos e ajuda.

Ao Conselho Nacional de Energia Nuclear (CNEN) pela bolsa concedida.

À todos, que de certa forma me ajudaram chegar até aqui. 
"Que os vossos esforços desafiem as impossibilidades $e$ lembrai-vos de que as grandes coisas do homem foram conquistadas do que parecia impossivel". 


\title{
USO DA RADIAÇÃO GAMA DO COBALTO-60 EM ÁCAROS DE IMPORTÂNCIA AGRÍCOLA VISANDO O TRATAMENTO QUARENTENÁRIO
}

\author{
André Ricardo Machi
}

\section{RESUMO}

O objetivo do trabalho foi estudar os efeitos da radiação gama nas fases do ciclo evolutivo de ácaros: Tetranychus urticae, Tetranychus desertorum, Oligonychus ilicis, visando o tratamento quarentenário como um método alternativo de controle. Para a realização do trabalho, ácaros das três espécies acondicionadas em bandejas plásticas medindo $20 \times 15 \mathrm{~cm}$ circundadas por algodão hidrofóbico e cola entomológica $\left(\right.$ Stick $^{\circledR}$ ) para evitar uma possível fuga dos ácaros. Posteriormente, cada espécie foi colocada separadamente dentro de gaiolas de madeiras revestidas com tela tipo organdi $(1,5 \times 1,5 \times 1,5 \mathrm{~m})$, e mantidos em casa de vegetação sob hospedeiro alternativo, plantas de Feijão de Porco (Canavalia ensiformis $L$ ) e folhas de café (Coffea arábica $L$ ) apenas para $O$. ilicis. Os ácaros foram identificados em um microscópio estereoscópico e transferidos com um pincel de ponta fina sobre placas de petri individualizadas com 1 acaro fêmea por placa (um total de 32 placas) contendo folhas de feijão de porco e folhas de café ( $C$. arábica $L$ ). A irradiação dos ácaros femeas foram feitas em um irradiador com fonte Cobalto-60, tipo Gammacell-220, sob uma taxa de dose $0.486 \mathrm{kGy} / \mathrm{hora}$, com doses de: 0 (controle) 100, 200, 300 e $400 \mathrm{~Gy}$, em um total de 5 tratamentos e 32 repetições para cada ácaro. As avaliações foram realizadas a cada 24 horas, por um período de 22 dias após a irradiação, contando-se o número de: ovos, ninfas, adultos e mortalidade dos ácaros. Para as análises estatísticas foram utilizados modelos lineares generalizados com distribuição do tipo quasebinomial e gaussiana para análise dos dados de proporções de mortalidade e duração em dias das fases de ovos e ninfas das três espécies de ácaros envolvidas no estudo. A verificação da qualidade do ajuste dos dados foi feita por meio do uso do gráfico meio-normal de probabilidades com envelope de simulação. Quando houve diferença significativa entre os tratamentos, múltiplas comparações (teste de Tukey, $P<0,05$ ) foram realizadas por meio da função 
glht do pacote multicomp com ajuste dos valores de $P$. Todas as análises foram realizadas utilizando-se o software estatístico "R", versão 2.15.1. A diminuição da viabilidade dos ovos e das ninfas dos ácaros foi diretamente proporcional ao aumento das doses de radiação gama. A dose de 200 Gy foi esterilizante para todas as fases do ciclo evolutivo de O.ilicis e 300 Gy para T.urticae e $T$. desertorum.

Palavras chave: Ácaros, Irradiação, Tratamento fitossanitário, Biologia 


\title{
USE OF GAMMA RADIATION OF COBALT-60 ON MITES IN AGRICULTURAL IMPORTANCE SEEKING TREATMENT QUARANTINE
}

\author{
André Ricardo Machi
}

\begin{abstract}
The objective of the study was evaluate the effects of gamma radiation on the stages of the life cycle of mites: Tetranychus urticae, Tetranychus desertorum, Oligonychus ilicis with the quarantine treatment as an alternative method of control. To realization of the research the mites were placed in plastic trays measuring $40 \times 27 \mathrm{~cm}$ surrounded by hydrophobic cotton moistened with water and entomological glue (Stick $\AA$ ). Each species was separately placed in cages of wood coated with organdy fabric type $(1.5 \times 1.5 \times 1.5 \mathrm{~m})$, and maintained in a greenhouse under alternate host plants Jack Bean (Canavalia ensiformis L) and in leaves of coffee (Coffea arabica L) only for O. ilicis. Each species of mite was identified in a stereoscope microscopic and transferred with a fine-tipped brush on separate petri dishes and individualized with 1 female mite per plate (a total of 32 plates) containing leaves of jack bean ( $C$. ensiformis $\mathrm{L})$ and leaves of coffee (C. Arabica $\mathrm{L})$. The irradiation the mites females were taken an irradiator of Cobalt- 60 source, Gammacell - 220 type using a dose rate of $0.486 \mathrm{kGy} /$ hour, with doses of 0 (Control) 100, 200, 300 and 400 Gy, with a total of 5 treatments and 32 replications by each mite. The evaluate were made the every 24 hours, for a period of 22 days after irradiation, counting the number of: eggs, nymphs and adult mortality of mites. For statistical analysis, were used generalized linear models with quasi-binomial distribution and Gaussian type for data analysis of proportions of mortality and duration in days of the stages of eggs and nymphs of the three species of mites were used in the study. The verification of the quality of adjustment of the data was done through the use of half-Normal Graphic of probabilities with envelope simulation. When significant differences among treatments, multiple comparisons (Tukey test, $P$ $<0.05$ ) were conducted by glht function multicomp package with adjustment of $P$ values All analyzes were performed using the statistical software "R", version 2.15.1. The results showed a decrease of the viability of the eggs and of the
\end{abstract}


nymphs of the mites that was directly proportional to the increase of the doses of gamma radiation and that the dose of 200 Gy was sterilizing for all phases of O.ilicis and 300 Gy to T.urticae and T. desertorum.

Key words: Mites, Irradiation, Phytossanitary treatment, Biology 


\section{SUMÁRIO}

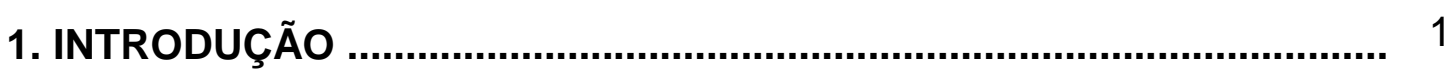

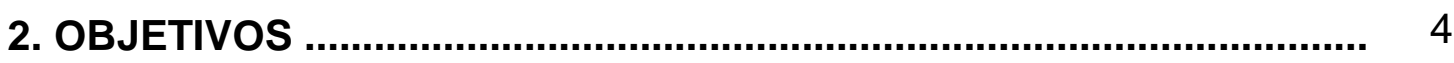

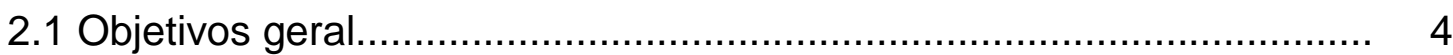

2.2 Objetivos específicos.................................................................... 4

3. REVISÃO BIBLIOGRÁFICA................................................................ 5

3.1 Situação da fruticultura brasileira e mundial.......................................... 5

3.2 Início do sucesso brasileiro............................................................

3.3 Cenário agrícola atual................................................................

3.4 Pragas agrícolas.................................................................... 10

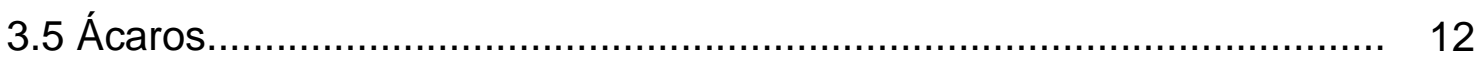

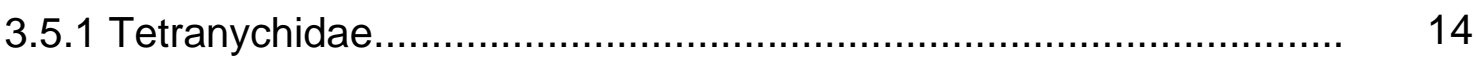

3.5.1.1 Tretanychus urticae (Koch,1836).............................................. 16

3.5.1.2 Tetranychus desertorum (Banks, 1900)..................................... 17

3.5.1.3 Tetranychus oligonychus ilicis (Mcgregor, 1917)............................ 18

3.6 Manejo Integrado de Pragas (MIP) ................................................. 18

3.7 Legislação Fitossanitária Brasileira ...................................................... 19

3.7.1 Trânsito Interestadual.................................................................... 19

3.7.2 Campanhas Fitossanitárias............................................................ 20

3.7.3 Trânsito Internacional............................................................... 20

3.8 Pragas de Importância Quarentenária................................................. 21

3.8.1 Análise de Risco de Pragas (ARP) .................................................. 21

3.8.2 Áreas Livres de Pragas (ALP) .................................................... 21

3.9 Tratamento Quarentenário por irradiação............................................ 22 
3.9.1 Regulamentações gerais sobre processo de irradiação de alimentos (ANVISA)

3.9.2 Instrução normativa no 9, de 24 de fevereiro de 2011 (MAPA)............. 28

3.9.3 Instrução normativa № 8 Hindu dos Citros (Schizotetranichus hindustanicus)

3.9.4 Instrução normativa nำ 9, de 24 de fevereiro de 2011 (MAPA)............ 29

4. MATERIAL E MÉTODOS .................................................................. 30

4.1 Coleta dos ácaros............................................................. 32

4.2 Criação Massal............................................................... 32

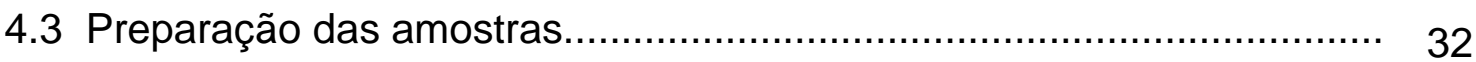

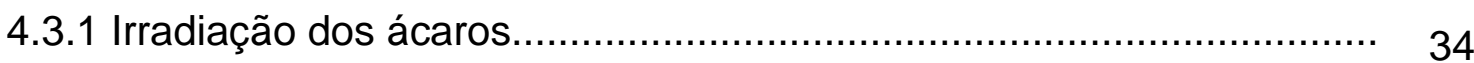

4.4 Avaliação das amostras...................................................... 35

4.5 Delineamento experimental e análises estatísticas......................... 35

5. RESULTADOS E DISCUSSÃO ....................................................... 37

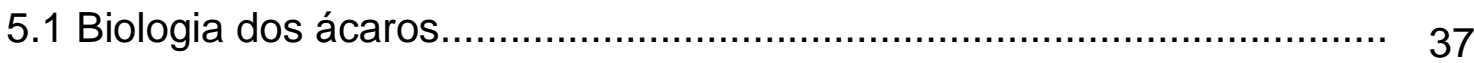

5.2 Estimativas da viabilidade e duração da fase de ovo....................... 37

5.3 Estimativas da Viabilidade e duração da fase de ninfas...................... 40

5.4 Efeitos da Radiação Gama na Biologia dos ácaros............................ 43

6. CONCLUSÕES .............................................................................. 46

REFERÊNCIAS BIBLIOGRÁFICAS...................................................... 47 


\section{LISTA DE TABELAS}

TABELA 1 - Médias ( \pm erro padrão) da viabilidade e duração da fase ovo de Tetranychus urticae expostos à radiação Gama nas diferentes doses (Gy) Temp.: $25 \pm 2{ }^{\circ} \mathrm{C}$; U.R.: $70 \pm 10 \%$. 37

TABELA 2 - Médias ( \pm erro padrão) da viabilidade e duração da fase ovo de Tetranychus desertorum expostos à radiação Gama nas diferentes doses (Gy)

Temp.: $25 \pm 2 \stackrel{\circ}{ } \mathrm{C}$; U.R.: $70 \pm 10 \%$. 38

TABELA 3 - Médias ( \pm erro padrão) da viabilidade e duração da fase ovo de Oligonychus ilicis expostos à radiação Gama nas diferentes doses (Gy) Temp.: $25 \pm 2{ }^{\circ} \mathrm{C}$; U.R.: $70 \pm 10 \%$.

TABELA 4 - Médias ( \pm erro padrão) da viabilidade e duração da fase ninfas de Tetranychus urticae expostos à radiação Gama nas diferentes doses (Gy) Temp.: $25 \pm 2 \stackrel{\circ}{ } \mathrm{C}$; U.R.: $70 \pm 10 \%$; fotofase $14 \mathrm{~h}$. 40

TABELA 5 - Médias ( \pm erro padrão) da viabilidade e duração da fase ninfas de Tetranychus desertorum expostos à radiação Gama nas diferentes doses (Gy) Temp.: $25 \pm 2 \stackrel{\circ}{\circ}$; U.R.: $70 \pm 10 \%$; fotofase $14 \mathrm{~h}$ 41

TABELA 6 - Médias ( \pm erro padrão) da viabilidade e duração da fase ninfas de Oligonychus ilicis expostos à radiação Gama nas diferentes doses (Gy) Temp.: $25 \pm 2 \stackrel{\circ}{ }$; U.R.: $70 \pm 10 \%$; fotofase $14 \mathrm{~h}$. 


\section{LISTA DE FIGURAS}

FIGURA 1 - Indicadores de Infra-estrutura. Adaptado de "The Global Competitiveness Report 2011-2012"....................................................... 10

FIGURA 2 - Ciclo biológico de ácaros da família tetranychidae....................... 17

FIGURA 3 - Danos de Tetranychus urticae................................................. 18

FIGURA 4 - Danos de Tetranychus desertorum............................................. 18

FIGURA 5 - Danos de Oligonychus ilicis....................................................... 19

FIGURA 6 - Infra-estrutura do trânsito brasileiro ........................................... 21

FIGURA 7 - Ação direta e indireta da radiação ionizante no DNA................... 23

FIGURA 8 - Poder de penetração das radiações - Adaptado de USEPA

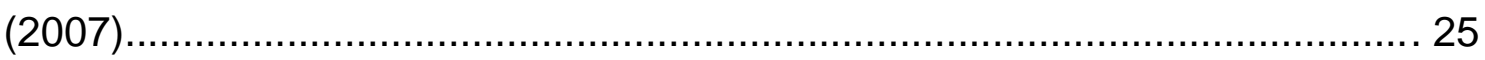

FIGURA 9 - Etapas realizadas para atingir as metas do projeto....................... 30

FIGURA 10 - Feijão de porco (Canavalia ensiformis L)................................. 32

FIGURA 11 - Transferência dos ácaros para placas de petri.......................... 32

FIGURA 12 - Placas de petri usadas na irradiação dos ácaros........................ 33

FIGURA 13 - Irradiador de Cobalto-60 usado no experimento......................... 34 


\section{INTRODUÇÃO}

A descoberta da agricultura tornou possível o suprimento contínuo de alimentos. Os problemas relacionados ao ataque de pragas vêm desde os primórdios da humanidade, quando no Oriente médio surgiram as primeiras atividades agrícolas. Atualmente, esse é um dos grandes entraves da agricultura moderna que tenta minimizar as perdas econômicas aliadas à crescente demanda mundial de alimentos.

O Brasil é um dos três maiores produtores mundiais de frutas, com uma produção que supera os 40,0 milhões de toneladas/ano atrás somente de países como Índia e China (SEAB, 2013).

Porém a produtividade e a qualidade desses produtos agrícolas são dependentes dos danos econômicos causados por insetos, ácaros e patógenos (LEVINE e D'ANTONIO, 2003).

Dentre outros, os desafios do mercado mundial para a exportação de mercadorias são os problemas fitossanitários, cujos agravantes englobam fatores adversos, de riscos ou ameaças à produção, produtividade e comercialização. Fato esse que justifica os grandes esforços nacionais e internacionais realizados para a modernização da agricultura, com o objetivo principal de combater pragas, doenças e plantas daninhas das culturas, além, obviamente, da necessidade de aumento da produção (FARIA, 1997).

Diante desse cenário, o Brasil tem aumentado suas exportações a cada ano com o objetivo de ampliar ainda mais esse mercado externo, produtores e exportadores buscam medidas que aumentem a segurança e a vida útil das frutas. Dentre os tratamentos usados estão os métodos químicos, como o brometo de metila que é usado no setor agrícola como fumigante biocida de amplo espectro para aplicaçao em pré-preparo de solos, commodities, materiais de embalagem de madeira visando insetos pragas, nematóides, plantas daninhas, patógenos e roedores.

Diferentemente da maioria dos pesticidas, o brometo de metila tem uma pressão de vapor elevada e são mais propensos a cair fora do local de aplicação (WOODROW e KRIEGER 2007). Estima-se que $30-50 \%$ das aplicações agrícolas de brometo de metila ficam retidos no ar e nào chegam as 
culturas. A inalação é a principal via de exposição de pessoas ao brometo de metila, concentrações altas no meio ambiente pode levar a doenças quando o indivíduo é exposto por um longo tempo ao brometo de metila. Uma amostra de 56 trabalhadores do sexo masculino, com exposição ao brometo de metila a longo prazo foram associado sintomas crônicos de tontura, dormência, pesadelos e fadiga efeitos neurotóxicos e câncer de prostata. Até o momento, poucos estudos avaliaram a exposição crônica brometo de metila (KISHI et al.,1991, COCKBURN et al., 2011).

Esse fumigante também foi identificado como um produto químico que contribui para a destruiçao da camada de ozônio estratosférico, Os problemas ambientais do brometo de metila (MeBr) são associados com a sua reatividade química. Por exemplo, o MeBr reage na estratosfera e libera bromo $(\mathrm{Br})$, que por sua vez reage com ozonio para formar oxigênio e óxido de bromo esgotando assim o ozonio da atmosfera. MeBr é agora reconhecido como um dos principais gases esgotam o ozônio na estratosfera e, no âmbito do Protocolo de Montreal (1992), o seu uso era para ser extinto até 2005 no mundo desenvolvido e mais tarde em 2015 nos países em desenvolvimento (por exemplo, Chile). No entanto, alguns países (por exemplo, Nova Zelândia), apesar da assinatura do Protocolo de Montreal, ainda usam MeBr para a fumigação na exportação de commodities, na verdade, uma revisão do uso de MeBr realizado pela Agência de Gestão de Risco Ambiental da Nova Zelândia em 2010, permite a importação e uso continuado de $\mathrm{MeBr}$ na Nova Zelândia com captura de gás que será introduzido em 2020 (ERMA, 2013). Por causa de preocupações sobre seu efeito, o brometo de metila foi proibido em 2005, pelo Protocolo de Montreal (UNEP, 2006, USEPA, 2013, GEMMILL et al., 2013).

As preocupações com o uso desenfreado de inseticidas vêm desde CAPALBO (1998) quando o autor nessa época já adiantava uma tendência mundial para as próximas décadas na redução do uso de inseticidas, motivado pôr fatores econômicos e ambientais.

Devido a esses problemas métodos alternativos de controle como o tratamento quarentenário vem sendo utilizados no combate "dos inimigos das plantas e das colheitas", e dentro destes, devido ao longo período de experimentação, a irradiação de pragas e alimentos, vem se destacando como um método alternativo no tratamento de pragas de importância agrícolas. 
A irradiação já é usada com sucesso como tratamento quarentenário para o controle de insetos (SILVA et al., 2010; HALLMAN e THOMAS 2010; HOSSAIN et al., 2011; HALLMAN et al., 2013; ARTHUR, 2012; ARTHUR et al., 2012)

Porém se tratando de ácaros de importância agrícola são poucos os trabalhos na área de irradiação. Essas pragas de um modo geral atacam praticamente todos os tipos de culturas no Brasil, tais como: Manga, Morango, Laranja, Lichia, Pepino, Berinjela, entre outras. Estudo sobre a irradiação de ácaros justifica-se pelo fato de compreenderem um grande número de artrópodes que causam prejuízos de milhões de dólares todos os anos com o uso de acaricidas para seu controle fitossanitário (SALVO FILHO, 1997; FLECHTMANN, 1975).

As novas exigências internacionais buscam o equilíbrio entre os processos produtivos e o meio ambiente, através da racionalização do uso de produtos químicos e a descoberta de novas técnicas alternativas, que visam, principalmente, a redução significativa da produção de resíduos (ARTHUR, 1997; MENDONÇA et. al., 2000).

Nesse novo contexto, surgiu o Manejo Integrado de Pragas (MIP) que segundo BOARETTO e BRANDÃO (2000) é uma filosofia de controle de pragas que procura preservar e incrementar os fatores de mortalidade natural, através do uso integrado de todas as técnicas possíveis de controle, selecionadas com base nos parâmetros econômicos, ecológicos e sociológicos. E no âmbito dos tratamentos quarentenários, surgiram novas técnicas como o manuseio da temperatura, gases, tratamento térmico e as radiações ionizantes para o controle efetivo de pragas, cuja principal vantagem é a não produção de resíduos, promovendo, dessa forma, a melhora na qualidade dos produtos comercializados, a proteção do meio ambiente e o enriquecimento da saúde humana. 


\section{OBJETIVO}

\subsection{Objetivo geral}

Estudar os efeitos da radiação gama nas fases do ciclo evolutivo de ácaros: Tetranychus urticae, Tetranychus desertorum, Oligonychus ilicis, visando o tratamento quarentenário como um método alternativo de controle.

\subsection{Objetivos específicos}

- Determinar as dose esterilizantes para cada espécie de ácaro.

- Estudar uma possível aplicação desta técnica em programas de manejo integrado de pragas, como tratamento fitossanitário desses ácaros.

- Determinar uma menor dose genérica de irradiação do que aquela exigida pela legislação da NINF 18 que atualmente é de 400 Gy. 


\section{REVISÃO BIBLIOGRÁFICA}

\subsection{Situação da fruticultura brasileira e mundial}

A produção mundial de frutas está em constante crescimento. No triênio $89 / 91$ era de 420,0 milhões de toneladas, ultrapassou os 500,0 milhões de toneladas em 1996 e em 2009 colheu-se um volume de 724,5 milhões de toneladas. A produção de 728,4 milhões de toneladas em 2010 é superior apenas em 0,5\%. A China, Índia e o Brasil são os maiores produtores de frutas (SEAB, 2013).

Uma das principais causas desse aumento na produtividade tem sido o crescimento populacional, que nos últimos dez anos registrou um aumento de $15,5 \%$, ultrapassando os 6,5 bilhões de habitantes. (FAO, 2011). De acordo com a FAO, nas próximas décadas o número de habitantes será de 9 bilhões de habitantes até 2050 e haverá a necessidade de se produzir $70-100 \%$ mais alimentos do que são produzidos hoje (GODFRAY et al., 2010).

Dados da (SEAB, 2013) mostram que a produção mundial de frutas no ano de 2012 foi de aproximadamente 728.4 milhões de toneladas, sendo que a fruta mais produzida foi a banana, seguida pela melancia e pela maça.

O Brasil é um dos maiores produtores e exportadores agrícolas do mundo. Em alguns setores como o café, soja e suco de laranja, o país tem sido um participante de grande sucesso no mercado internacional, mas exporta relativamente pouco de suas frutas. A classificação do Brasil entre os maiores exportadores de frutas ainda é baixo, visto o montante das frutas que é produzida no país. Além dos mercados já consolidados para a exportação das frutas brasileiras, como, por exemplo, a União Européia, que só em 2007 importou mais de $85 \%$ do total das frutas exportadas pelo país. Devido a essa grande quantidade de frutas produzidas, o Brasil necessita buscar novos negócios entre os novos mercados em potencial, como o Canadá, um dos maiores importadores de frutas do mundo, visto que não é um grande produtor (CEPEA, 2011). 
Esse status de grande produtor está associado tanto a fatores climáticos como territoriais, pois o Brasil tem a capacidade de dispor de áreas capazes de produzir o ano inteiro, e também apresenta condições climáticas diversificadas que favorecem o cultivo de um grande e variado número de espécies, além de possuir a tecnologia necessária para produzir frutas que possam competir no mercado internacional (CEPEA, 2011).

Além disso, a procura cada vez maior por alimentos saudáveis, devido à globalização do "culto ao corpo e vida saudável", vem lotando academias e varejões. Nesse sentido, o setor de produção de frutos tem se tornado um dos mais importantes segmentos do agronegócio brasileiro, constituindo uma rendosa alternativa para $\mathrm{o}$ avanço das exportações brasileiras de produtos agrícolas (FAO, 2013).

A Laranja é a principal fruta produzida no Brasil, com 19,8 milhões de toneladas saídas dos pomares em 2011 , e responde por $43,9 \%$ do volume total da Fruticultura, um acréscimo na produção em 9,4\% em relação a 2010. A laranja, a banana e o abacaxi são as três frutas mais exportadas e juntas respondem por 69\% em 2012 (SEAB, 2013).

A produção brasileira de frutas deve somar 43 milhões de toneladas em 2013, com ligeiro aumento, de 1,65\%, em comparação ao volume produzido no ano passado, (ANUÁRIO BRASILEIRO DA FRUTICULTURA, 2013).

Segundo Instituto Brasileiro de Frutas - IBRAF, o consumo de frutas no Brasil já se equipara ao dos países desenvolvidos, com aproximadamente 67 $\mathrm{kg}$ por habitante/ano (incluindo frutas in natura, desidratadas, congeladas e sob a forma de suco). Porém para que o Brasil aumente sua produção e se aproxime dos maiores países produtores (Índia e China), é preciso reduzir as perdas ao longo de sua cadeia produtiva para poder atender e elevar as exportações (IBRAF, 2007). 


\subsection{Início do sucesso brasileiro}

A agricultura no Brasil surgiu de povos indígenas no período pré colonial, e, após a chegada dos Portugueses em 1500 dC, e foi praticada por subsistência e baixa produtividade até a década de 1960 (SANTOS, 1988). Durante o período, as principais culturas de exportação eram a cana de açúcar e o café mas já eram cutlivados mandioca, milho e batata-doce (LINHARES, 1995).

A partir da década de 1960 , houve uma mudança nas políticas agrícolas brasileiras que visaram a modernização tecnológica para aumentar a produtividade da terra e do trabalho. Este objetivo foi alcançado através do uso de uma maior quantidade insumos básicos e mecanização, estimulos de mais créditos agrícolas e o estabelecimento de preços e incentivos à exportação ( RODRIGUES, 1987; BARROS et al., 2009 ).

Essas políticas eram parte de uma estratégia para impulsionar o crescimento econômico e diminuir as importações (BARROS et al., 2009).

\subsection{Cenário agrícola atual}

Atualmente, a agricultura e a pecuária são os setores agrícolas mais produtivos do país e estão entre os principais geradores de riqueza no país, representando 113.800 milhões de dólares em 2010, ou $4,9 \%$ do produto interno bruto (PIB) (IBGE, 2010). Sendo que a produção e a exportação de commodities tem uma boa representaçao nesse mercado. Assim, o Brasil tornou-se um dos principais produtores e exportadores de alimentos. Este resultado deve-se principalmente a investimentos de longo prazo em tecnologia agrícola , com conseqüente aumento da produtividade (BARROS et al., 2009). Hoje, o Brasil é um dos maiores produtores mundiais de cana (açúcar e álcool ), café , milho, soja , oleaginosas, uvas, laranjas (frutas frescas e sucos ), carne bovina, suína e de aves (USDA, 2011).

Diante dessa perspectiva, os novos desafios para a fruticultura brasileira são a expansão dos Estados produtores, o aumento de áreas plantadas, 
aumento de logística e infra-estrutura para se produzir mais alimentos (NOVAES, 2008).

A agricultura brasileira está caracterizada por grandes fluxos de importação e exportação, que estão aliados com as vastas terras do país e 15.700 quilômetros de fronteiras com 10 países vizinhos da América do Sul (IBGE, 2011).

Para a conquista de novos mercados são necessárias mudanças como devido a variações climáticas e questões logísticas e fez com que houvesse uma migração das culturas entre os diferentes Estados brasileiros. A banana tornou-se mais viável nos estados de Minas Gerais, São Paulo e Bahia. O estado do Ceará é estratégico, pois por conta de sua localidade os custos logísticos são reduzidos já que se localiza mais próximo de pólos importadores como os Estados Unidos e a União Européia. No caso do mamão, que antes era cultivado no Espírito Santo, passou a ser produzido no Rio Grande do Norte e no Ceará, devido à redução de custos logísticos, já que o transporte que era realizado por meio do modal aéreo passou a ser efetuado pelo modal marítimo, que além de ser menos custoso teve seu tempo de trânsito reduzido (ANUÁRIO BRASILEIRO DA FRUTICULTURA, 2009).

De acordo com VITTI (2009), o acréscimo da receita é conseqüência da expansão dos mercados e da maior agilidade na logística de distribuição que permite que as frutas cheguem ao destino final com sua qualidade assegurada e a preços mais competitivos. O crescimento das exportações brasileiras é resultado de maiores investimentos em tecnologia e a conquista de novos mercados.

A tendência é de que o mercado mundial de frutas continue crescendo por conta do comportamento apresentado pelos consumidores e preocupação com a saúde e bem estar, fazendo com que demandem por mais frutas, já que são alimentos saudáveis. Condições socioeconômicas, tais como aumento na renda, estilo de vida urbanizado e mais acesso à informação e à educação também contribuem para o crescimento da demanda de frutas (VITTI, 2009).

Porém, ainda o Brasil possui grandes entraves para poder atender a demanda mundial de frutas que surgirão nos próximos anos.

Apesar de alguns avanços, os últimos balanços do Programa de Aceleração do Crescimento (PAC) revelam que as obras portuárias já 
concluídas representam $25 \%$ do investimento total de $\mathrm{R} \$ 5,3$ bilhões prevista para o setor. Paralelamente, recente estudo do Fórum Econômico Mundial classificou a qualidade da infra-estrutura portuária brasileira na 130 posição em um ranking de 142 nações. Atrás de todos os países do BRICS (que reúne, além do Brasil, Rússia, Índia, China e África do Sul) e de dois dos principais parceiros comerciais vizinhos - Argentina e Chile (FIG. 1).

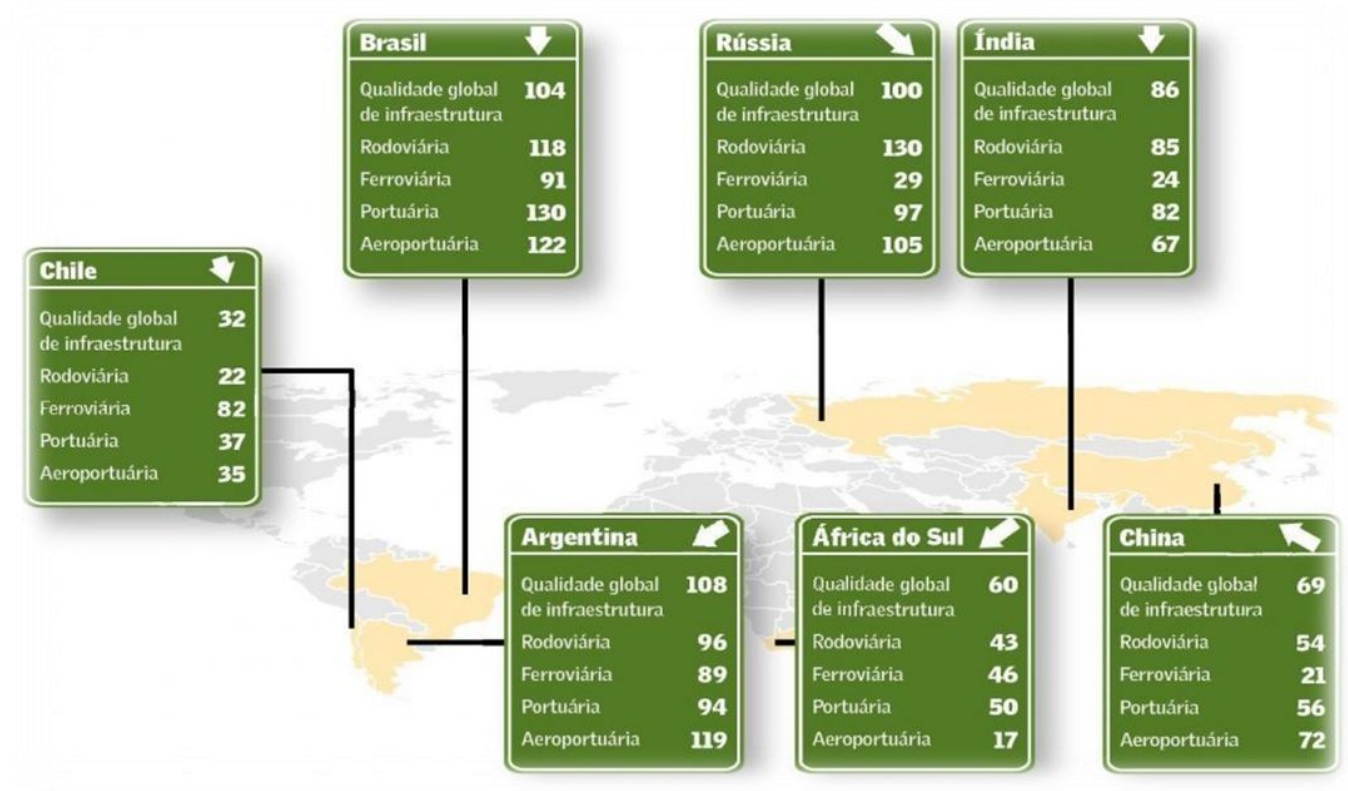

FIGURA 1 - Indicadores de Infra-estrutura. Adaptado de "The Global Competitiveness Report 2011-2012"

Segundo os autores (NACHREINER et al., 2003; PASSONI et al., 2006), muitos fatores refletem a participação do Brasil na exportação de frutas, como:

a) Imposição de barreiras fitossanitárias por outros países importadores, principalmente pelos EUA;

b) Elevadas tarifas e impostos cobrados durante toda a cadeia de frutas, altas taxas de juros para determinadas operações que são necessárias ao longo da cadeia. Enquanto a atuação da Organização Mundial do Comércio - OMC não produzir os efeitos desejados em termos de paridade tributária aos produtos 
agrícolas, o governo brasileiro terá que adotar políticas nesta área de modo a não reduzir a competitividade das frutas e derivados no mercado internacional;

c) A inexistência de uma política de defesa fitossanitária em âmbito nacional;

d) Qualidade inadequada às exigências dos compradores internacionais, além de expressivo mercado doméstico de algumas frutas, que contribui para certa negligência do setor produtivo, repercutindo em não adequação das frutas produzidas no que diz respeito às variedades exigidas no mercado externo;

e) Falta de um programa de marketing sobre as frutas tropicais, já que estas são desconhecidas por grande parte da população de outros continentes como Europa;

f) A precária infra-estrutura de estradas, portos e aeroportos, influenciando negativamente no escoamento da produção e aumentando as perdas no processo;

g) Irregularidade de oferta do produto para os consumidores internacionais, acarretando em problemas de permanência no mercado e dificultando contratos que assegurem a manutenção das cotas de comercialização.

Alguns dos mercados potenciais que poderiam ser mais explorados pelo Brasil para as exportações são o Canadá, os Estados Unidos, os Emirados Árabes e a Rússia, mas para isso é necessário uma melhora da infra-estrutura brasileira em toda a cadeia produtiva e minimizando perdas.

\subsection{Pragas agrícolas}

A relação entre monocultura e agricultores ao longo do tempo tem formado uma combinação impactante ao meio ambiente, tendo como principais cultivos a cana, a soja, as hortaliças, as frutíferas dentre outros, os ambientes agrícolas do agronegócio requerem a utilização cada vez maior de agrotóxicos para combater pragas e garantir uma maior produtividade (CAMACHO, 2010).

O desflorestamento de uma área causa a quebra do equilíbrio entre meio ambiente $\mathrm{x}$ pragas pelo isolamento da área cultivada, pela movimentação e a troca de germoplasma vegetal, esses fatores contribuem para o aumento populacional imediato de determinadas espécies de insetos-praga, patógenos e plantas daninhas nos ambientes agrícolas pelo fornecimento abundante de 
hospedeiros (alimentos) ou condições ambientais favoráveis. Assim, os fatores físicos, químicos e biológicos e o tipo de manejo das culturas determinam a abundância e a predominância de espécies presentes nos ambientes agrícolas e seus impactos na produção e qualidade dos produtos colhidos (WAQUIL, s.d.).

Atualmente, o comércio mundial de commodities agrícolas está crescendo rapidamente, assim como o transporte de produtos entre países exportadores e importadores, devido a isso o risco de introdução de insetos exóticos em novas áreas onde eles podem se tornar pragas de plantas também aumenta (BARROS et al., 2009).

O Brasil enfrenta diversas perdas ao longo da sua cadeia produtiva como: a baixa infra-estrutura, os padrões insustentáveis de produção, o baixo consumo interno de frutas (Não atende a demanda mundial de frutas grande produtor e baixas vendas) e ainda problemas relacionados com pragas.

Os fitófagos são as pragas que causam os maiores danos agrícolas, onde se encontram insetos e ácaros que se alimentam da planta, dos frutos e podem ser transportados juntamente com seus hospedeiros, ou relacionado às (commodities) que são expedidas e exportadas. (WESTPHAL et al., 2008).

Alem disso as espécies exóticas causam prejuízos ambientais que podem afetar os ecossistemas, modificando o comportamento ecológico e interações entre as espécies que muitas vezes resulta em mudanças profundas nas espécies, incluindo extinçoes de faunas nativas e alterações diretas nos processos dos ecossistemas que controlam atividades das plantas e dos animais (NELSON et al., 2010).

Segundo PIMENTEL et al., (2002) o estabelecimento de novas pragas pode custar caro a um país, devido ao aumento da destruição de culturas, desenvolvimento de novos programas de controle e restrições de quarentena no comércio. Nos Estados Unidos por exemplo, os danos anuais causados por insetos e ácaros exóticos já foram estimados em> $\$ 17$ bilhoes de dólares.

Em uma escala global, estima-se que os prejuízo da introduçao de pragas pode causar perdas de $7,9-15,1 \%$ de grandes colheitas (METCALF, 1996; OERKE, 2006).

No Brasil, as perdas estimadas para as principais culturas variam entre $2 \%$ e $30 \%$ (BENTO, 1999), com as perdas econômicas anuais no valor de 
cerca de $\$ 12$ bilhões de dólares. Desse total, cerca de $13,7 \%$ ou 1.600 milhões dólares são as perdas são causadas por espécies exóticas. No entanto, esse percentual deve ser mais elevado, pois não existem estimativas para a maioria de espécies de insetos e ácaros introduzidas no país.

Essas características colocam o país em um risco elevado para a introdução de espécies exóticas, incluindo microrganismos, plantas e animais. Particularmente insetos e ácaros destacam-se por causa de seu pequeno tamanho e grande capacidade de sobreviver em condições desfavoráveis durante o transporte e armazenagem de produtos agrícolas e de hospedeiros de plantas, além de elevada capacidade para a dispersão e colonização de novos ambientes (KIRITANI e YAMAMURA 2003; BOUNFOUR et al., 2005).

\section{5 Ácaros}

Os aracnídeos compreendem um dos clados mais diversificados de quelicerados amplamente documentados, sendo, nas faunas atuais ou como fósseis, sobre uma longa e profícua história geológica (NORTON et al., 1988).

Dentre esses, os ácaros compreendem um grande número de artrópodes incluídos na subclasse Acari da classe Arachinida, da qual pertencem escorpiões, aranhas, opiliões e carrapatos (FLECHTMANN, 1975).

Os primeiros ácaros surgiram na terra após a Era Pré - Cambriana, sendo o primeiro fóssil datado do período Devoniano (aproximadamente 400 milhões de anos atrás) e identificado como Protocarus crani, mas a maioria dos fósseis foi encontrada no Oligoceno (Período terciário da Era Cenozóica, aproximadamente 12 milhões de anos atrás), e tudo leva a crer que os ácaros são provenientes do ancestral comum dos Opiliões (NORTON et al., 1988).

Os ácaros são encontrados em vários ambientes acessíveis à vida animal: solo, parte aérea das plantas, pêlos e penas de animais; existem também ácaros de folículos nos poros do homem, correntes de água, insetos hospedeiros e até no oceano (FLECHTMANN, 1975).

Os ácaros fitófagos são espécies que se alimentam da parte aérea e subterrânea das plantas, podendo causar prejuízos econômicos a diversas culturas de valor comercial, com destaque para indivíduos da família 
tetranychidae, que engloba cerca de $60 \%$ das espécies de ácaros fitófagos pragas de importância agrícola mundial (FLECHTMANN, 1975, 1979; SATO, 2006; EVANS, 1992).

Os ácaros estão entre os grupos de maior diversidade no planeta, sendo hoje conhecidas mais de 45.000 espécies e havendo estimativas de que possam existir mais de 500.000 , fato esse, que dificulta o controle de todas as espécies, necessitando assim de maiores pesquisas nessa área (ADIS, 2001).

IGNATOWICZ (1997) afirma que sensibilidade de insetos e ácaros à irradiação varia de acordo com o estágio de desenvolvimento no momento do tratamento. Em geral, estágios juvenis têm grande sensibilidade como também grande atividade de divisão celular. Estudos anteriores determinaram que as ninfas e adultos de Tyrophagus putrescentiae, irradiados com doses de 1,5 e 2 kGy podem chegar a 100\% de mortalidade, mas que uma dose de 260 Gy é eficaz na prevenção das futuras gerações.

Para Tetranychus cinnabarinus Boisduval 320 Gy (IGNATOWICZ e BANASIK-SOLGALA,1999) e o eriofiídeo Phyllocoptruta oleivora Ashmead,uma praga importante de frutas cítricas (Citrus spp.) na China, 350 Gy (HU et al., 2004).

Segundo HALLMAN (1998) ácaros fêmeas da espécie Tetranychus urticae Koch são mais tolerantes a esterilidade causada pela irradiação do que machos.

Esse fato pode estar relacionado à partenogênese, mas, infelizmente, não há nenhum exemplo de radiação que induz esterilidade dos insetos de características partenogenéticas com o qual comparar. Para outros ácaros, como o Rhizoglyphus achinopus, a dose entre 500 e 600 Gy é necessária para inibir a reprodução (HALLMAN, 1998).

No Brasil, o primeiro trabalho realizado com irradiação de ácaros para tratamento quarentenário foi o de MINEIRO e ARTHUR (2003), que irradiaram ácaros T. urticae e determinaram que nas doses de 250, 300 e 400 Gy a mortalidade dos ácaros foi maior que $80 \%$, OSOULI et al.,(2013) observou que 300Gy foi a dose esterilizante para T.urticae em flores, estes estudos indicam que os ácaros podem ser geralmente mais tolerantes a radiação do que os insetos. MACHI et al., (2012), irradiaram fêmeas adultas de T. urticae visando uma possível esterilização dessa espécie de ácaro com doses de radiação de: 
0 (controle), 100, 200, 300 e 400 Gy. Pelos resultados obtidos concluíram que a dose de 300 Gy foi esterilizante para as fêmeas adultas, podendo essa dose de radiação gama ser indicada para o controle fitossanitário dessa espécie de acaro.

Ácaros das famílias Eriophyidae, Tarsonemidae, Tenuipalpidae e Tetranychidae são pragas quarentenárias e para as quais tratamentos fitossanitários de pós-colheita são frequentemente necessários. A dose para estas pragas poderiam ser de pelo menos 350 Gy ao invés das doses genéricas de 400 Gy exigidas atualmente (HEATHER e HALLMAN 2008; HALLMAN, 2011).

\subsubsection{Tetranychidae}

As especies dessa familia geralmente possuem caracter'isticas distintas, os ovos podem possuir formas esférica, ovóide, cilíndrico e globuloso. Ao nascer as larvas sao incolores e translucidas e possuem aproximadamente 0 tamanho dos ovos, sua cor pode de verde clara chegando gradativamente at'e verde escuro `a medida que se alimenta.

A fase de protoninfa e a Deutoninfa são maiores que a larva, sendo a primeira possuindo a cor esverdeada e a segunda uma cor verde ou rósea dependendo da espécie do ácaro, nesse estágio pode-se diferenciar ácaros que darão origem a fêmeas ou a machos As fêmeas são maiores que os machos possuem manchas rajadas como duas faixas negras ou vermelhas mais pronunciadas do que os machos. As fêmeas medem entre 0,4 e $0,5 \mathrm{~mm}$ de comprimento, já o macho e um pouco menor (MORAES e FLECHTMANN, 2008).

Esses ácaros possuem características haplo-diplóides, ou seja, os machos podem ser produzidos por partenogênese arrenótoca e as fêmeas através de reprodução sexuada. Algumas espécies apresentam partenogênese telítoca (NORTON et al., 1993).

Um dos grandes problemas relacionados aos ácaros da espécie tetranychidade é seu grande número de hospedeiros que são pragas de plantas cultivadas que causam sérios danos. O catálogo de BOLLAND et 
al.,(1998) apresentou 1.189 espécies em 71 gêneros de pragas dessa espécie no mundo e cerca de 54 só no Brasil (YANINEK e MORAES, 1991).

Além disso, alguns ácaros dessa família apresentam especificidade em relação a seu hospedeiro sendo restrito a apenas um tipo de cultura como, por exemplo: Oligonychus ilicis McGregor em cafeeiro, Panonychus ulmi Koch em rosácea, Panonychus citri McGregor em citrus sp.

Alguns sinais de ocorrência de tetraniquídeos em culturas são a formação de teias, sendo muito intensa nessa espécie, a função das teias são variadas como proteção contra outros ácaros predadores onde muitos não conseguem se movimentar pelas teias, em algumas espécies as teias parece impedir a colonização de outros ácaros, ainda as teias conferem proteção contra a chuva já que as gotículas atingem com menor impacto as colônias ou não atingem, é importante para facilitar o encontro da fêmea pelo macho na reprodução e na dispersão para novos lugares, pois podem ser carregadas pela força do vento desprendendo o ácaro dessa teia e levando-o para outra planta. Em outros tetraniquídeos como alguns Oligonychus que se desenvolvem na face superior das folhas, as teias produzidas fixam-se na folha e com o passar dos dias as folhas ganham um aspecto "empoeirado" pois essas teias retêm e fixam partículas de pó (MORAES e FLECHTMANN, 2008).

Quando os ácaros dessa espécie atingem uma grande densidade populacional, esses tendem a migrar-se para plantas mais novas ou outros ambientes, a rápida dispersão de ácaros só é possível pela ação do homem que os levam consigo através de produtos vegetais, por exemplo. Essa também é uma das causas da introdução de pragas exóticas no país desses tetraniquídeos em lugares relativamente distantes, um dos estudos mais bem sucedidos de tetraniquídeos foi realizado na África com a espécie Mononychellus tanajoa Bondar, segundo YANINEK (1988) houve dispersões a longas distâncias desse ácaro em manivas e folhas de mandioca que foram transportadas naquele ano, no estudo realizado foi demonstrada uma persistência de 60 dias em manivas de mandioca desprovidas de folhas.

No geral o ciclo de desenvolvimento de ácaros dessa família de ovo a adulto varia em média de 5 a 50 dias (dependendo da temperatura), e aproximadamente 6,2 dias a $29,4^{\circ} \mathrm{C}$. Cada fêmea coloca em média 40 ovos (podendo chegar a 140 ovos) durante a sua vida (JEPPSON et al.,1975). 
O ciclo biológico dos ácaros dos tetraniquídeos geralmente compreende 5 etapas (FIG.2).

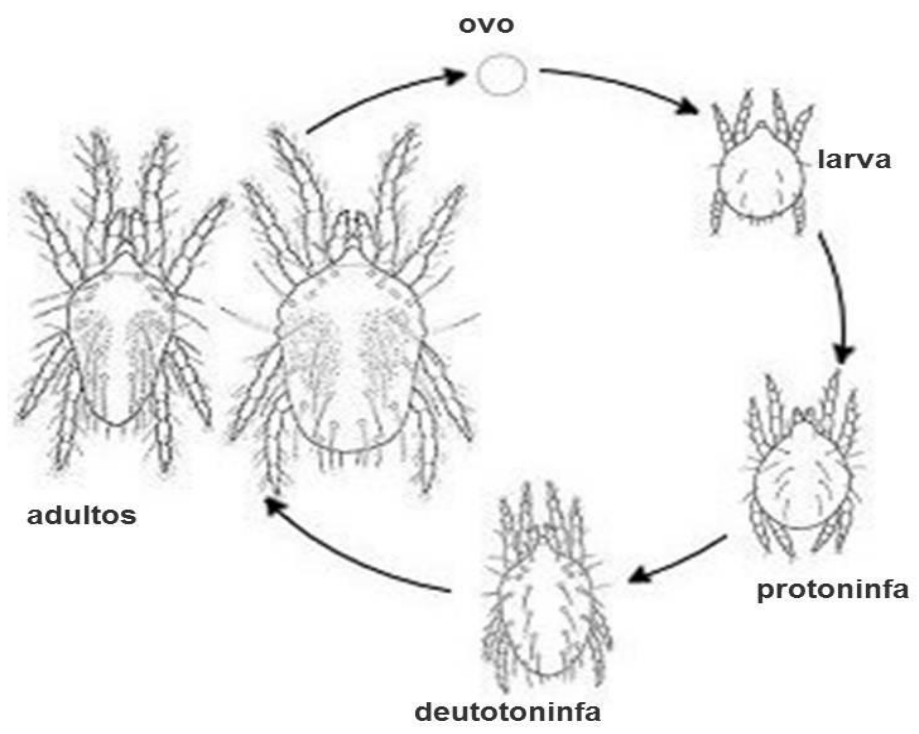

FIGURA 2 - Ciclo biológico de ácaros da família tetranychidae

\subsubsection{Tetranychus urticae (Koch, 1836)}

Essa espécie já é bastante conhecida e estudada devido a seus diversos danos, em países de clima tropical como o Brasil, as fêmeas dessa espécie possuem uma cor esverdeada, com um par de manchas laterais escuras (FIG.3). Já em regiões temperadas apresentam a cor avermelhada e os adultos são hibernantes no inverno desses locais. O ácaro rajado como também é conhecido, é uma espécie cosmopolita que ataca uma grande diversidade de plantas cultivadas ou não e por essa razão é considerada uma das mais importantes pragas no mundo (MORAES e FLECHTMANN, 2008). 

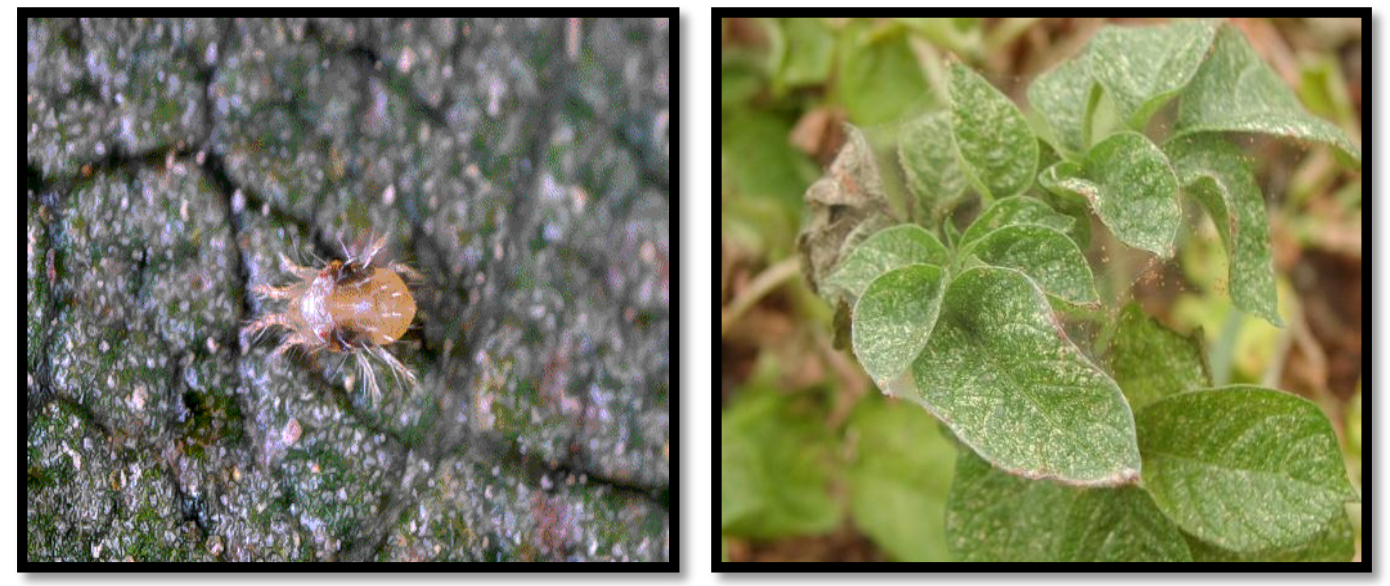

FIGURA 3 - Danos de Tetranychus urticae

Fonte: http://www.daylilies.org/ahs_dictionary/spider_mites.html

\subsubsection{Tetranychus desertorum (Banks, 1900)}

O ácaro-vermelho, T.desertorum é uma espécie polífaga e ataca diversas culturas semelhantes a T.urticae, tem sido relatado em 173 espécies de plantas e encontram-se distribuídos na Argentina, Brasil, China, Estados Unidos, Hawai, México e Venezuela, entre outros países (BOLLAND et al., 1998). Esse ácaro causa danos na região mediana da folha (FIG.4).
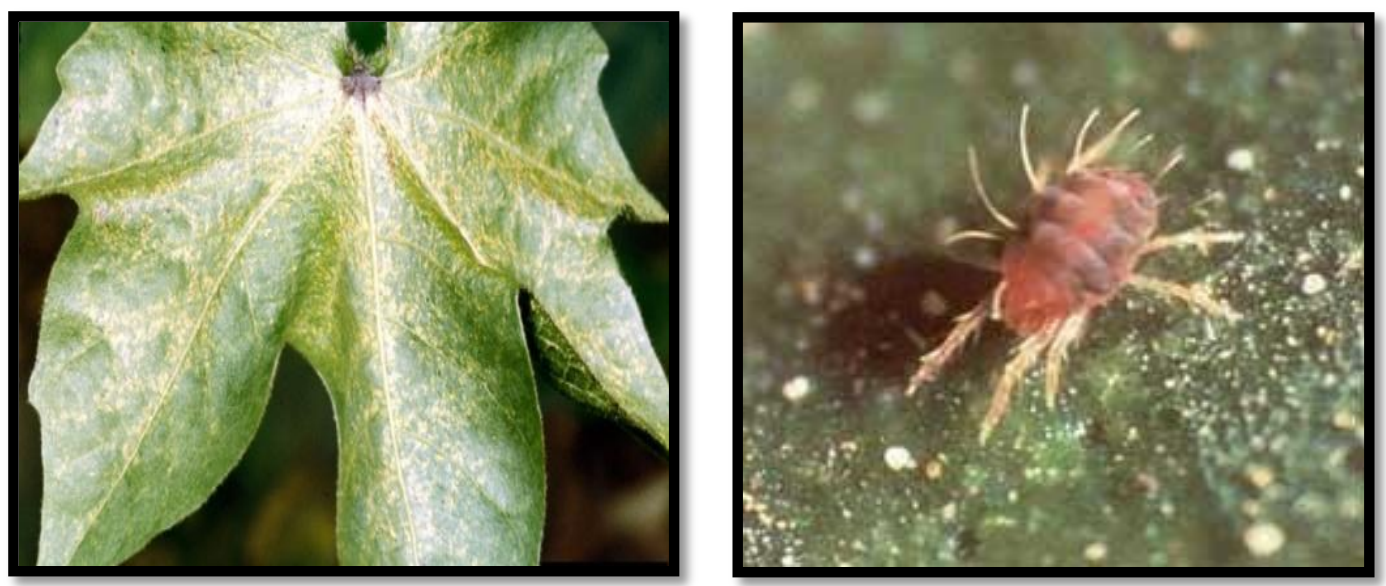

FIGURA 4 - Danos de Tetranychus desertorum Fonte: www.agrolink.com.br 


\subsubsection{Oligonychus ilicis (McGregor, 1917)}

Ë popularmente conhecido com ácaro vermelho do cafeeiro e encontrado na face superior das folhas que, quando atacadas (FIG.5), apresentam-se recobertas por uma delicada teia, tecida pelos próprios ácaros, onde aderem detritos, poeira e suas exúvias, provenientes do processo de ecdise após os estádios quiescentes, dando às folhas um aspecto de sujeira. Para se alimentar, perfuram células da epiderme e do mesófilo e absorvem o conteúdo celular extravasado (REIS, 2005; MORAES e FLECHTMANN, 2008).
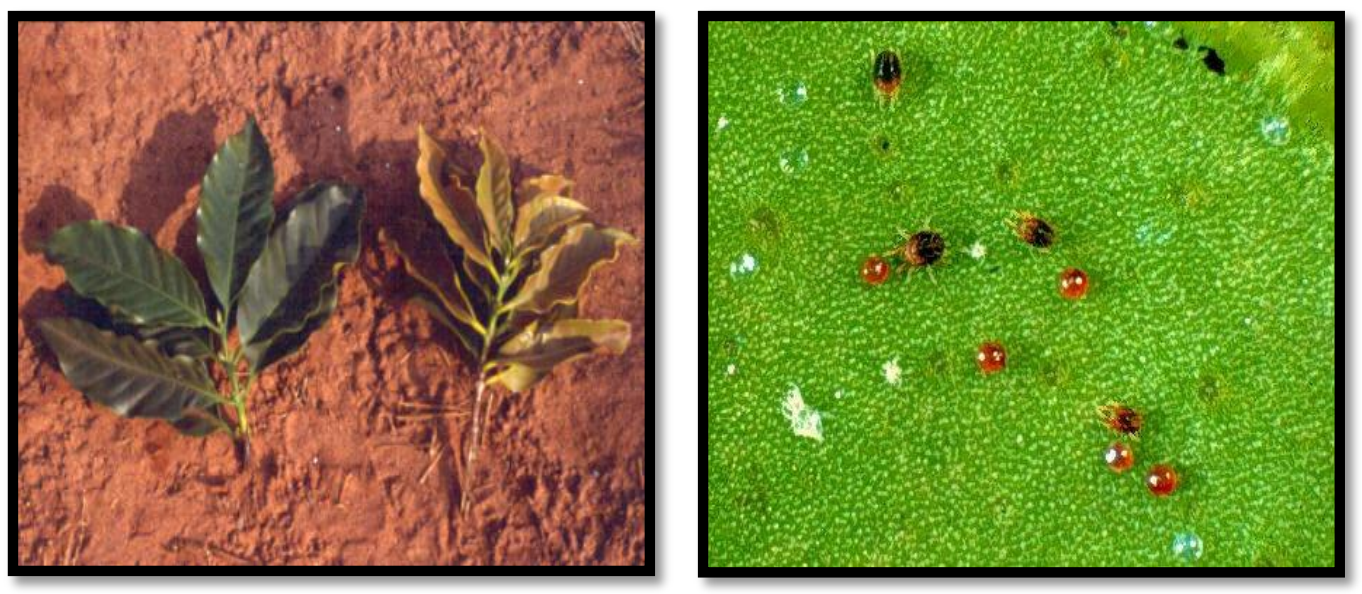

FIGURA 5 - Danos de Oligonychus ilicis

Fonte: http://www.ces.ncsu.edu/depts/ent/notes/O\&T/trees/ort077e/img_sorm.htm

\subsection{Manejo Integrado de Praga (MIP)}

O Manejo Integrado de Pragas (MIP) é uma filosofia de controle de pragas que procura preservar e incrementar os fatores de mortalidade natural, através do uso integrado de todas as técnicas de combate possíveis, selecionadas com base nos parâmetros econômicos, ecológicos e sociológicos. Visa manter 0 nível populacional dos insetos numa condição abaixo do nível de dano econômico, através da utilização simultânea de diferentes técnicas ou táticas de controle, de forma econômica e harmoniosa com o ambiente (ANVISA, 2013). 


\subsection{Legislação Fitossanitária Brasileira}

A Legislação Fitossanitária Brasileira apresenta dois grandes segmentos: Legislação Básica e Legislação Complementar. A básica: estabelece os princípios fundamentais que orientam toda a conduta governamental na área de proteção fitossanitária. Ela é constituída pelos seguintes instrumentos legais: 1. Regulamento de Defesa Sanitária Vegetal (RDSV) - (Decreto 24114/34) - estabelece as normas e procedimentos adotados pelo país para importação, exportação, comércio, transporte, erradicações e combate a pragas, desinfecção e desinfestação de vegetais. 2. Convenção Internacional de Proteção Fitossanitária (CIPF) - tem o objetivo de assegurar uma ação comum e permanente contra a introdução e disseminação de pragas relacionadas a vegetais. 3. Lei dos Agrotóxicos (Lei 7802/89 e Decreto 98816/90) - dispõe sobre a pesquisa, experimentação, produção, embalagem, transporte, armazenamento, comercialização, utilização, exportação, importação, destinação final de resíduos e embalagens, registro, classificação, controle, inspeção e fiscalização de agrotóxicos, seus compostos e afins. A lei Complementar: Estabelece ou regulamenta as normas, procedimentos e estrutura operativa da Defesa Sanitária do país. Constitui-se de portarias, decretos e leis que são atualizadas periodicamente (ANVISA, 2013).

\subsubsection{Trânsito Interestadual}

São normalizados pela Legislação Complementar, que estabelece restrições e procedimentos a serem seguidos sempre que ocorre risco de disseminação de uma praga de importância quarentenária. Devido a dificuldades operacionais, e também a grande extensão territorial, a fiscalização do trânsito interno somente é realizada quando faz parte de um programa de campanha, ou seja, quando esta atividade é indispensável para evitar a disseminação de uma praga que esta restrita a uma determinada região (ANVISA, 2013). 


\subsubsection{Campanhas Fitossanitárias}

É uma união de esforços para prevenir, controlar ou erradicar alguma ocorrência de ordem fitossanitária, através de estabelecimentos de normas e procedimentos específicos, o objetivo básico desse tipo de campanha é a resolução imediata e emergencial de problemas fitossanitários que possam afetar as culturas de expressão econômica (ANVISA, 2013).

\subsubsection{Trânsito Internacional}

A função de inspeção e fiscalização desse trânsito, de acordo com a legislação brasileira e com convenções internacionais, é responsabilidade da União, mais especificamente do Departamento de Defesa e Inspeção Vegetal (DDIV) que está subordinado ao MAPA. A execução dessas, são realizadas através dos postos de vigilância fitossanitária que estão presentes em aeroportos, portos, fronteiras rodoviárias e aduanas (FIG. 6). Deve-se ressaltar que para a exportação de vegetais, além de atender a legislação interna do país exportador, é obrigatório que as exigências fitossanitárias do país importador também sejam atendidas (ANVISA, 2013).

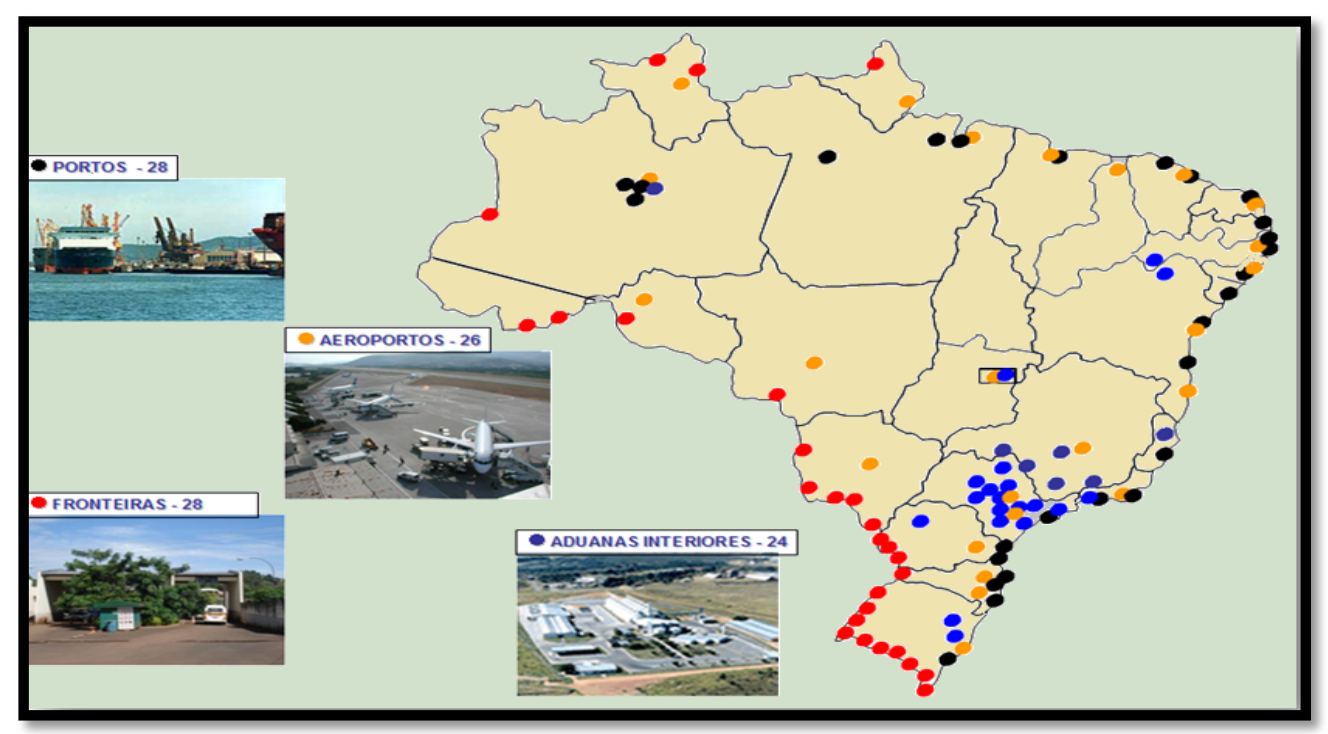

FIGURA 6 - Infra-estrutura do trânsito brasileiro 


\subsection{Pragas de Importância Quarentenária}

Segundo (ANVISA, 2011) são aquelas que podem ter importância econômica potencial para uma área posta em perigo, quando uma determinada praga não esta presente ainda ou, se presente, não está disseminada e se encontra sob controle oficial. Para identificar como tal uma determinada praga, devem-se utilizar definições adotadas pela $\mathrm{FAO}$, cujos princípios incluem considerações sobre a presença ou ausência da praga em uma área de perigo, a distribuição, a importância econômica e seu controle. Devem-se considerar critérios tais como: potencial de disseminação, potencial de estabelecimento e potencial de adequação climática. Assim sendo, as pragas definidas como quarentenárias enquadram-se nas seguintes categorias:

- A1 - Pragas exóticas, isto é, não presentes em determinadas áreas.

- A2 - Pragas de disseminação localizada.

\subsubsection{Análise de Risco de Pragas (ARP)}

Consiste em três fases: o início do processo para analise de risco: que envolve a identificação da praga de vias de ingresso; a avaliação do risco da praga: determina se consiste em uma praga de qualidade ou nociva (caracterizada em termos de sua importância econômica) ou se trata de uma praga não passível de regulamentação fitossanitária; manejo de risco da praga que engloba desenvolver, avaliar, comparar e relacionar opções para reduzir ou controlar o risco (ANVISA, 2013).

\subsection{2 Áreas Livres de Pragas (ALP)}

Objetivo é facilitar o transporte de vegetais e/ou produtos vegetais entre essas áreas, de tal forma que não sejam necessárias medidas fitossanitárias adicionais. Pode ser um país inteiro ou apenas uma área de determinado país que atendam os requisitos para tal determinação. Geralmente está relacionada 
à biologia da praga quarentenária em questão. Requisitos para estabelecimento e uso de ALPs como medida fitossanitária podem incluir: prospecção (delimitação, detecção e monitoramento), regularização e controle, auditoria (revisão e avaliação) e documentação (informes, planos de trabalho, dentre outros) (ANVISA, 2013).

\subsection{Tratamento Quarentenário por irradiação}

Trata-se de um processo físico de tratamento que consiste em submeter os alimentos, já embalado ou a granel, a doses controladas de radiação ionizante com finalidades sanitária, fitossanitária e ou tecnológica. Vale lembrar que a irradiação não pode substituir os agrotóxicos usados em campo isso porque 0 tratamento quarentenário por irradiação é um processo pós-colheita (ARTHUR, 1997, 1998 e 2004).

Radiações ionizantes são aquelas cujas energias são suficientemente altas para desalojar os elétrons dos átomos e moléculas, convertendo-os em íons. Seu princípio consiste no fato de que quando a matéria é atravessada por qualquer forma de radiação ionizante, pares de íons são produzidos e átomos e moléculas são excitados, havendo absorção de parte dessa energia transferida. Estes pares de íons podem ter energia suficiente para produzir novas ionizações e excitações. Estas ionizações são as responsáveis pelos efeitos biológicos das radiações. Em insetos e ácaros, por exemplo, a radiação gama promove danos ao ácido desoxirribonucléico (DNA) que podem ser fatais à célula. As lesões no DNA que não induzem a morte celular, devido aos mecanismos fisiológicos de reparação celular, podem ser transmitidas para as gerações de células futuras, iniciando-se o processo de neoplasia celular (DOWD e TILSON,1999).

$\mathrm{Na}$ ação indireta ocorrem sucessivas interações da radiação incidente com as diversas moléculas presentes no interior celular, destacando-se a água e o oxigênio (DOWD e TILSON, 1999). Essa interação é mais freqüente do que a interação direta, devido à abundância de água presente no meio celular (METTLER JUNIOR e UPTON, 1995). 
A primeira etapa da ação indireta da radiação gama é o processo da radiólise da água. Neste processo, são gerados espécies reativas primárias $\left(\mathrm{OH}^{*}, \overline{\mathrm{e}}_{\mathrm{aq}}, \mathrm{H}^{*}\right)$ e, produtos moleculares $\left(\mathrm{H}_{2}, \mathrm{H}_{2} \mathrm{O}_{2}\right)$, denominados "produtos primários da radiólise da água". Altamente reativos, os produtos primários interagem com as moléculas presentes no meio (FIG. 7) ou sofrem recombinações, desencadeando uma série de reações tóxicas para as células que promovem alterações químicas e biológicas (FAJARDO et al., 2001; GETOFF, 1996).

A radiólise da água é um processo contínuo, e está representado pela seguinte equação:

$$
\mathrm{H}_{2} \mathrm{O}+\text { radiação } \Rightarrow \mathrm{OH}^{\bullet}+\mathrm{H}^{\bullet}+\mathrm{H}_{2} \mathrm{O}_{2}+\overline{\mathrm{e}} \text { aq } \mathrm{H}_{2}+\mathrm{H}_{3} \mathrm{O}^{+}
$$

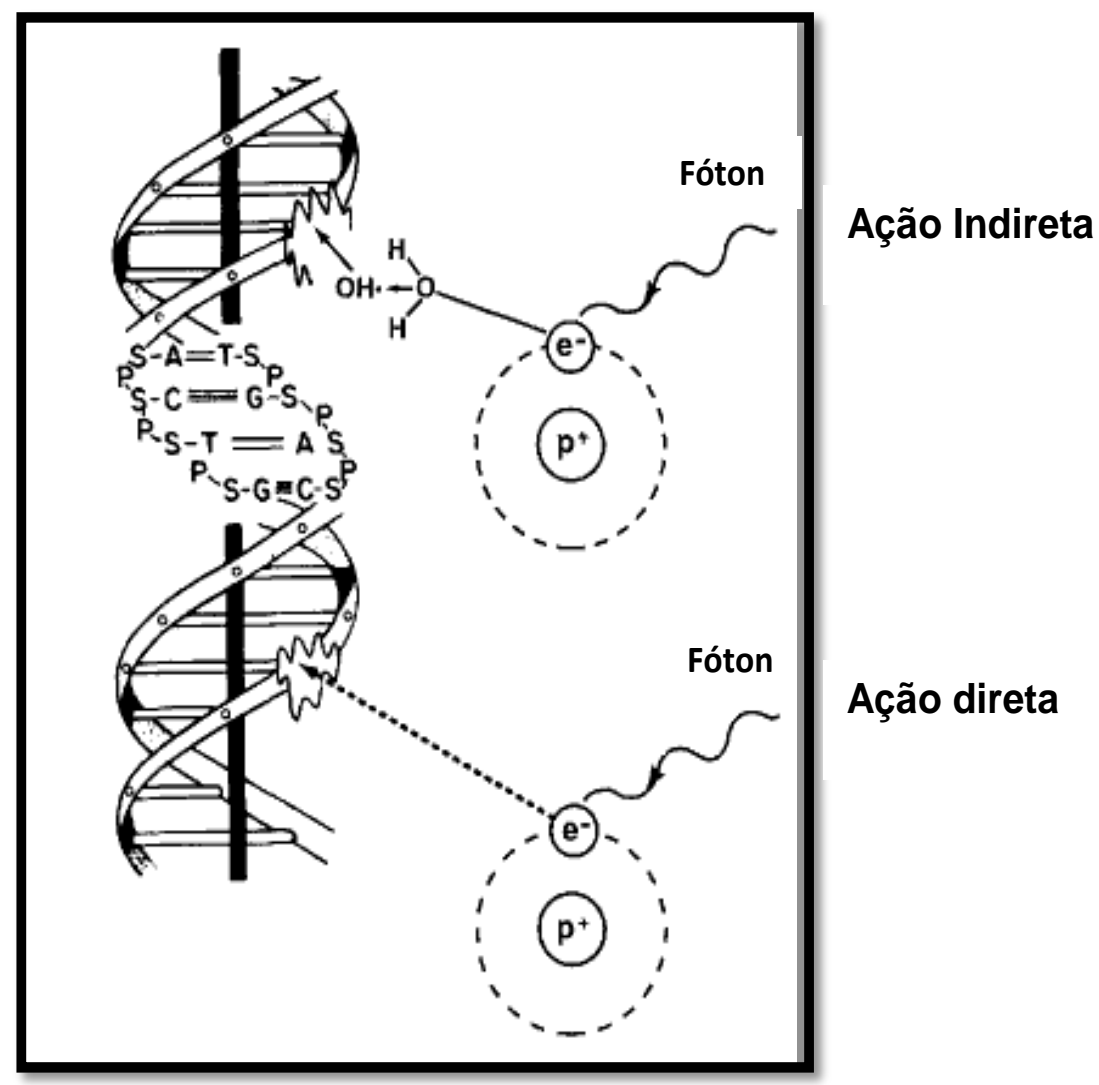

FIGURA 7 - Ação direta e indireta da radiação ionizante no DNA 
A radiação gama, radiação ionizante do tipo eletromagnética com elevada energia de penetração, interage mais freqüentemente com os organismos vivos pela ação indireta (METTLER JUNIOR e UPTON, 1995).

Diversos experimentos realizados em diferentes organismos evidenciaram que a sensibilidade à radiação ionizante depende da fase do ciclo celular em que as células se encontram quando irradiadas. Em geral, a maioria das células é considerada mais sensível durante a fase de mitose e mais resistente no período tardio da fase de síntese. Logo, uma mesma linhagem celular pode apresentar diferenças quanto à sensibilidade à radiação devido à distribuição das células nas diferentes fases do ciclo celular (METTLER JUNIOR e UPTON, 1995).

Existem três tipos de radiações ionizantes que são emitidos durante 0 decaimento radioativo (FIG. 8).

- Partículas a são formadas por dois prótons e dois nêutrons. São massivas e altamente energéticas, mas se propagam lentamente pelo ar. São emitidas, por exemplo, pelos radionuclídeos Urânio-238, Rádio226 e Polônio-210 (USEPA, 2007).

- As partículas $\beta$ são elétrons que se movem rapidamente durante 0 decaimento radioativo. Seres humanos estão expostos a partículas $\beta$ a partir de fontes artificiais e naturais de radiação, como o Trítio, Carbono14 e Estrôncio-90 (USEPA, 2007).

- Os raios y são fótons eletromagnéticos sem massa ou carga elétrica, mas possuem alto poder de penetração na matéria. Uma das fontes naturais de radiação gama é o Potássio-40, e as fontes artificiais são, por exemplo, o Cobalto-60 e o Césio-137. A diferença entre estes dois radionuclídeos quanto a emissão de raios gama está na quantidade de energia, onde o Césio-137 possui $662 \mathrm{keV}$ e o Cobalto-60 possui entre 1170 e 1330 keV (USEPA, 2007; HINTON, 2002). 


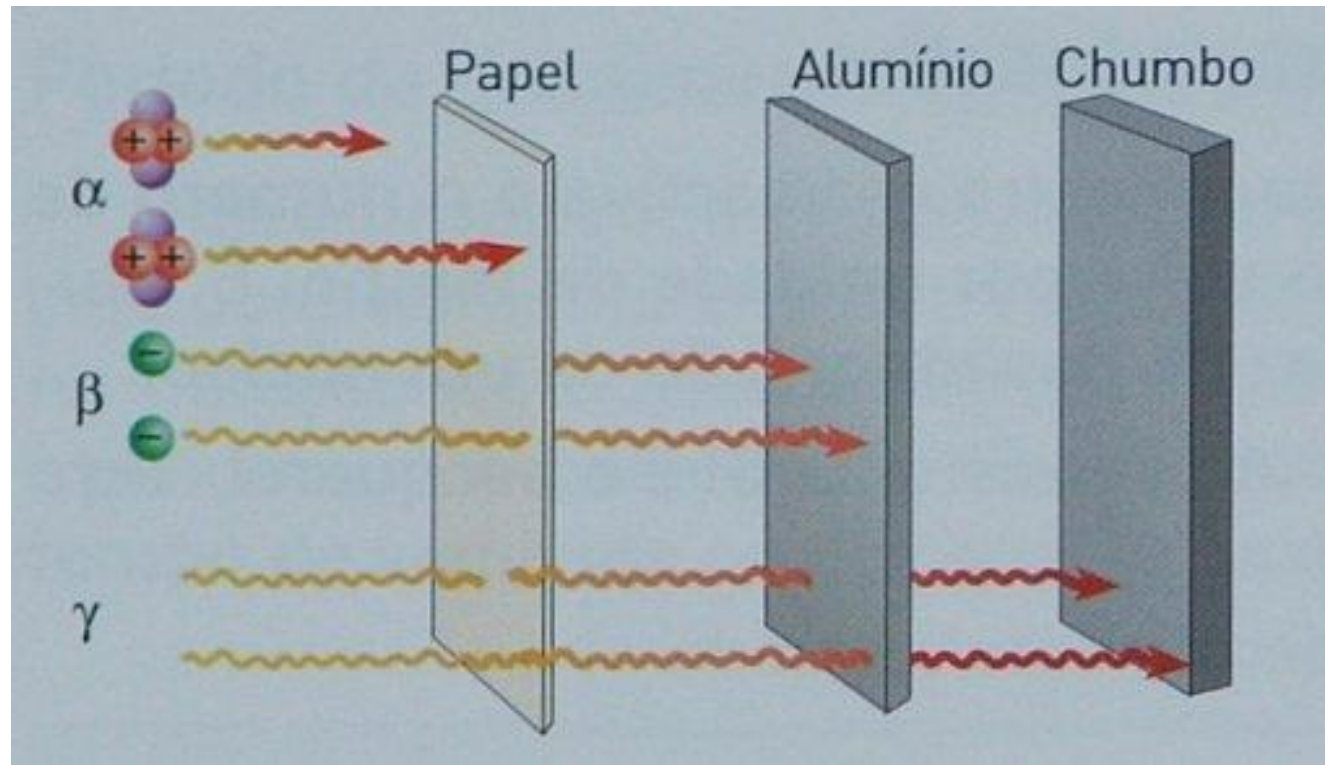

FIGURA 8 - Poder de penetração das radiações - Adaptado de USEPA (2007).

A radiação pode ter diversos usos e de acordo com as doses aplicadas, a irradiação pode duplicar ou triplicar o tempo de estocagem de produtos alimentícios, por exemplo - permitindo seu transporte por longas distâncias, matar insetos e ácaros invasivos das frutas e vegetais, e combater a contaminação resultante da falta de higiene na produção de carnes industrializadas eliminando os patógenos de origem alimentar (FIOCRUZ, 2011).

Segundo WIENDL, (1997); COUTO e SANTIAGO, (2010) os efeitos observados após o tratamento com irradiação, são os seguintes:

- Inibição do brotamento em bulbos e tubérculos

- Retardo da maturação de frutas e legumes

- Desinfestação de grãos, cereais, frutas e especiarias

- Redução da carga microbiana (fungos, bactérias e leveduras)

- Eliminação de microrganismos patogênicos (Salmonella spp e outros)

- Esterilização

Além disso, a irradiação vem sendo promovida como um substitutivo para o brometo de metila, um agrotóxico usado para controlar insetos, ervas daninhas 
e outros organismos patogênicos em mais de cem culturas (IAEA, 1982; DIEHL, 1992; ARTHUR, 1997).

O ICGFI (International Consultive Group of Food Irradiation), patrocinado pela Organização Mundial da Saúde (OMS); a Food and Agricultural Organization (FAO) e a Agência International de Energia Atômica (IAEA) posicionaram-se favoravelmente sobre a salubridade de alimentos irradiados, já a partir de 1980, e vêm estudando a irradiação de alimentos e fornecendo subsídios tecnológicos e científicos para a aprovação internacional de irradiação de alimentos (FARKAS, 1983; EMBRARAD, 2011).

\subsubsection{Regulamentações gerais sobre a irradiação de alimentos (ANVISA)}

No Brasil, a regulamentação em vigor sobre os processos de irradiação é a estabelecida pela Agência Nacional de Vigilância Sanitária (ANVISA) em 2001 (Resolução RDC № 21 de 26 de janeiro de 2001).

Segundo essa norma, o tratamento dos alimentos por irradiação deve ser realizado em instalações licenciadas pela autoridade competente estadual ou municipal ou do Distrito Federal mediante expedição de Alvará Sanitário, após autorização da Comissão Nacional de Energia Nuclear (CNEN) e cadastramento no órgão competente do Ministério da Saúde.

As fontes de radiação autorizadas pela Comissão Nacional de Energia Nuclear são:

- Isótopos radioativos emissores de radiação gama: Cobalto 60 e Césio 137 ;

- Raios $\mathrm{X}$ gerados por máquinas que trabalham com energias de até 5 $\mathrm{MeV}$;

- Elétrons gerados por máquinas que trabalham com energias de até $10 \mathrm{MeV}$.

Os alimentos poderão ser tratados por radiação desde que sejam observadas as seguintes condições: 
- A dose mínima absorvida deve ser suficiente para alcançar a finalidade pretendida e a dose máxima deve ser inferior àquela que comprometeria as propriedades funcionais e ou os atributos sensoriais do alimento.

- Na rotulagem dos alimentos irradiados, além dos dizeres exigidos para os alimentos em geral e específicos do alimento, deve constar no painel principal: "ALIMENTO TRATADO POR PROCESSO DE IRRADIAÇÃO", com as letras de tamanho não inferior a um terço (1/3) do da letra de maior tamanho nos dizeres de rotulagem.

- Quando um produto irradiado é utilizado como ingrediente em outro alimento, deve ser declarada essa circunstância na lista de ingredientes, entre parênteses, após o nome do mesmo.

Tal resolução estabelece ainda que as instalações devam ser autorizadas e inspecionadas pela Comissão Nacional de Energia Nuclear (CNEN).

"A irradiação, assim como qualquer outro processo de tratamento de alimentos, não deve ser utilizada em substituição as boas práticas de fabricação e ou agrícolas." (ANVISA, 2011).

\subsubsection{Instrução Normativa MAPA no 9, de 24 de fevereiro de 2011}

A irradiação de alimentos possui normas mais antigas que regulam 0 seu uso, porém a irradiação de pragas para fins fitossanitários ainda é relativamente nova. Essa norma visa suprir uma deficiência do país em relação à falta de uma política fitossanitária nacional. A Norma Internacional para Medidas Fitossanitárias - NIMF no 18 tem como orientação o uso da irradiação como medida fitossanitária com o objetivo de prevenir a introdução ou disseminação de pragas quarentenárias regulamentadas no território brasileiro.

A radiação ionizante como tratamento fitossanitário para fins quarentenários poderá ser utilizada para o gerenciamento do risco de pragas.-A irradiação ionizante pode ser usada a fim de obter certas respostas na praga objeto, tais como:

I - mortalidade; 
II - impedir o desenvolvimento bem-sucedido;

III - incapacidade para reprodução; e

IV - inativação.

Para tratamento fitossanitário com fins quarentenários, a radiação ionizante poderá ser fornecida por:

I - isótopos radioativos (raios gama de cobalto-60);

II - elétrons acelerados com energia máxima de $10 \mathrm{MeV}$; e III - por meio de raios-X com energia de até $5 \mathrm{MeV}$.

A irradiação poderá ser usada como um tratamento único ou combinado com outros tratamentos como parte integrante de um sistema de medidas fitossanitárias para o gerenciamento de risco de pragas a fim de satisfazer o nível de eficácia exigido. O risco de praga será prevista em protocolo de tratamento por radiação estabelecido por plano de trabalho bilateral entre a Organização Nacional de Proteção Fitossanitária do Brasil (ONPF) e as de outros países.

$\mathrm{Na}$ inspeção de exportação, a fim de atender os critérios fitossanitários estabelecidos pela ONPF do país de destino, em Plano de Trabalho Bilateral firmado com a ONPF do Brasil, a irradiação deverá ser utilizada como opção de gerenciamento de risco. Os registros deverão especificar, no mínimo, a origem dos produtos tratados, a finalidade do tratamento, dose utilizada, praga alvo do tratamento, tamanho e identificação do lote e informações sobre a rotulagem do produto (MAPA, 2011).

Para algumas espécies de ácaros que são quarentenários, já existem controles de trânsito para circular no território nacional, como:

3.9.3 Instrução Normativa № 8 Hindu dos Citros (Schizotetranichus hindustanicus)

Para o ácaro Hindu dos Citros (Schizotetranichus hindustanicus), é proibido o trânsito de vegetais e suas partes, exceto material in vitro e madeira 
serrada, das espécies de Citrus spp., Cocos nucifera, Acacia sp., Azadirachta indica, Melia azedarach e Sorghum bicolor, quando oriundas de Unidades da Federação (UF) onde seja constatada, por laudo laboratorial oficial, a presença da praga ( MAPA, 2011).

3.9.4 Instrução Normativa № 9 - Ácaro vermelho das palmeiras (Raoiella indica)

Estabelecer as normas de controle do trânsito de plantas e suas partes, exceto material in vitro, hospedeiras do ácaro vermelho das palmeiras (Raoiella indica). São plantas hospedeiras do ácaro aquelas das famílias Musaceae, Heliconiaceae, Strelitziaceae, Zingiberaceae e Palmae (Arecaceae) (MAPA 2011).

\section{MATERIAL E MÉTODOS}

A presente pesquisa foi realizada no Laboratório de Radiobiologia e Ambiente, no Centro de Energia Nuclear na Agricultura (CENA/USP), da Universidade de São Paulo, Piracicaba - SP, o experimento foi realizado em duas etapas.

Na primeira etapa foram feitos testes para se determinar doses mínimas e máximas, para observar a radio-resistência dos ácaros.

$\mathrm{Na}$ segunda etapa foram avaliados os efeitos dessas doses nos organismos irradiados e não irradiados com radiação ionizante. Posteriormente procurou-se determinar a dose sub-esterilizante de radiação gama na avaliando-se a viabilidade dos ovos dos ácaros irradiados. O esquema abaixo mostra as etapas realizadas o experimento (FIG. 9). 


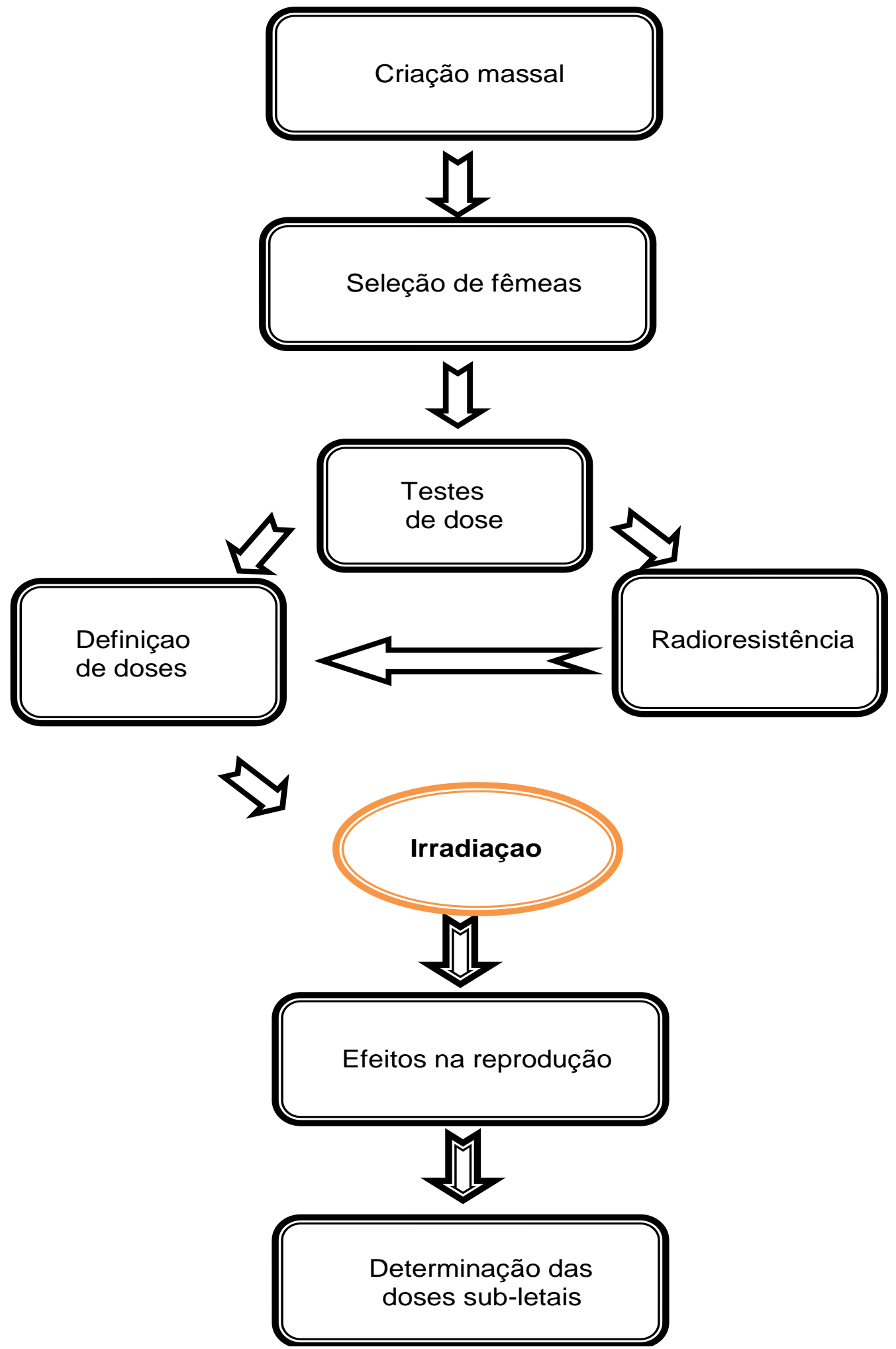

FIGURA 9 - Etapas realizadas para atingir as metas do projeto 


\subsection{Coleta dos ácaros}

Os ácaros usados nesse experimento foram obtidos de uma criação massal mantida em laboratório há mais de 3 anos, cedidos pelo departamento de Acarologia da Escola Superior de Agricultura de "Luiz de Queiroz" (ESALQ/USP), Piracicaba-SP e Instituto Biológico de Campinas (IB), Campinas-SP.

\subsection{Criação Massal}

Após a obtenção das colônias de Tetranychus urticae (Koch), Tetranychus desertorum (Banks), Oligonychus ilicis (McGregor), elas foram acondicionadas em bandejas plásticas medindo $40 \times 27 \mathrm{~cm}$ circundadas por algodão hidrofóbico e cola entomológica $\left(\right.$ Stick $\left.^{\circledR}\right)$ para evitar uma possível fuga dos ácaros.

Posteriormente, cada espécie foi colocada separadamente dentro de gaiolas de madeiras revestidas com tela tipo organdi $(1,5 \times 1,5 \times 1,5 \mathrm{~m})$, e mantidos em casa de vegetação sob hospedeiro alternativo, plantas de Feijão de Porco (Canavalia ensiformis L) e em folhas de café (Coffea arábica L) apenas para Oligonychus ilicis.

\subsection{Preparação das amostras}

Foram usadas plantas de feijão de porco infestadas com ácaros da própria criação massal para a obtenção de fêmeas adultas grávidas (FIG. 10). 

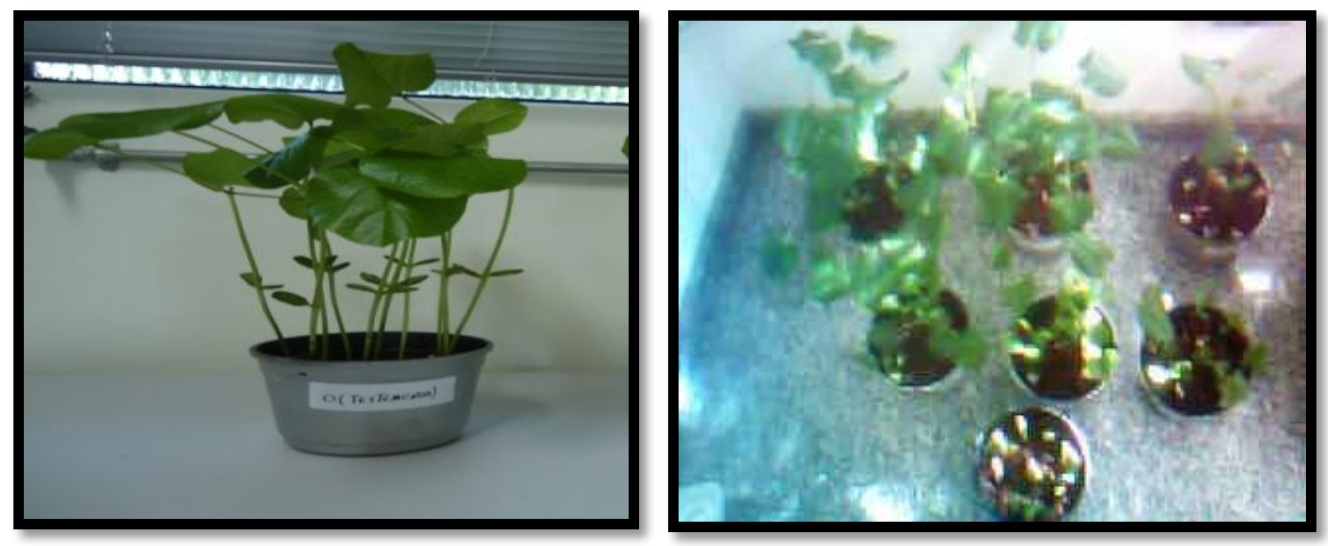

FIGURA 10 - Feijão de porco (Canavalia ensiformis L)

Posteriormente, cada espécie de ácaros foi identificada em um microscópio estereoscópico e transferidas com um pincel de ponta fina (FIG. 11) sobre placas de petri separadas e individualizadas com 1 acaro fêmea por placa (num total de 32 placas) contendo folhas de feijão de porco (Canavalia ensiformis L) com exceção para Oligonychus ilicis onde os mesmos testes foram realizados em folhas de café (Coffea arábica L).

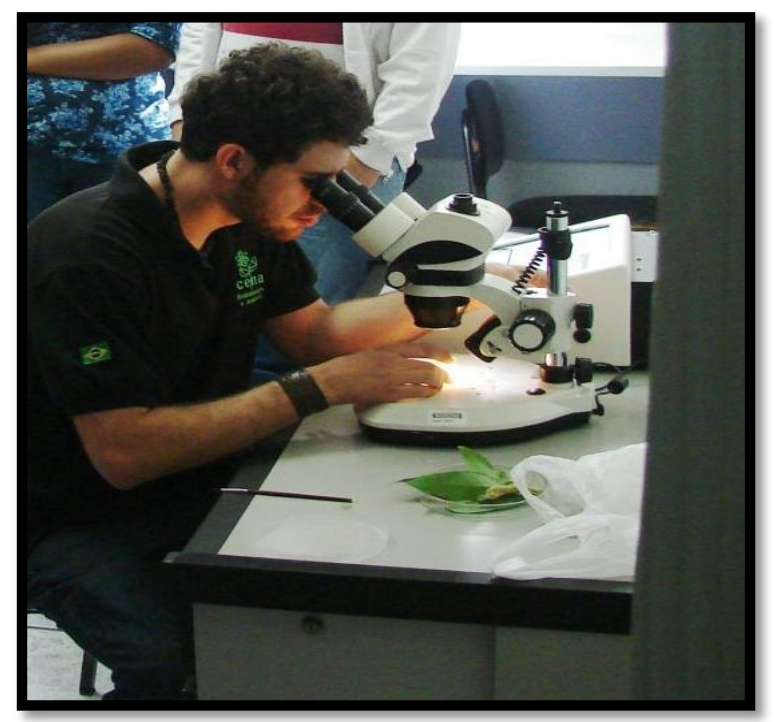

FIGURA 11 - Transferência dos ácaros para placas de petri 


\subsubsection{Irradiação dos ácaros}

Após a oviposiçao dessas fêmeas grávidas, os ovos foram transferidos para outras placas de petri contendo folhas de feijão de porco e aguardou-se a passagem para a última fase de ninfa na qual se determina o sexo desses ácaros (deutoninfa) e das fêmeas adultas, e posteriormente foram irradiadas (FIG. 12)

Para irradiação dessas placas de petri contendo os ácaros femeas foi utilizado um irradiador de Cobalto-60, tipo Gammacell-220, (FIG. 13) sob uma taxa de dose $0.486 \mathrm{kGy} /$ hora.

Cada espécie de acaro foi irradiada nas doses de: 0 (controle) 100, 200, 300 e 400 Gy, num total de 5 tratamentos, com 32 repetições por tratamento para cada ácaro fêmea.

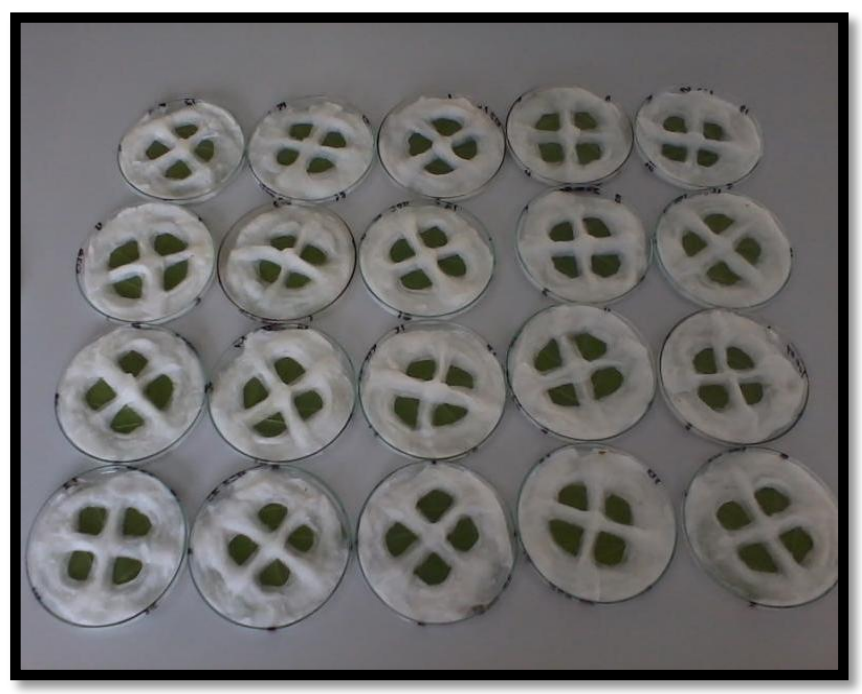

FIGURA 12 - Placas de petri usadas na irradiação dos àcaros 


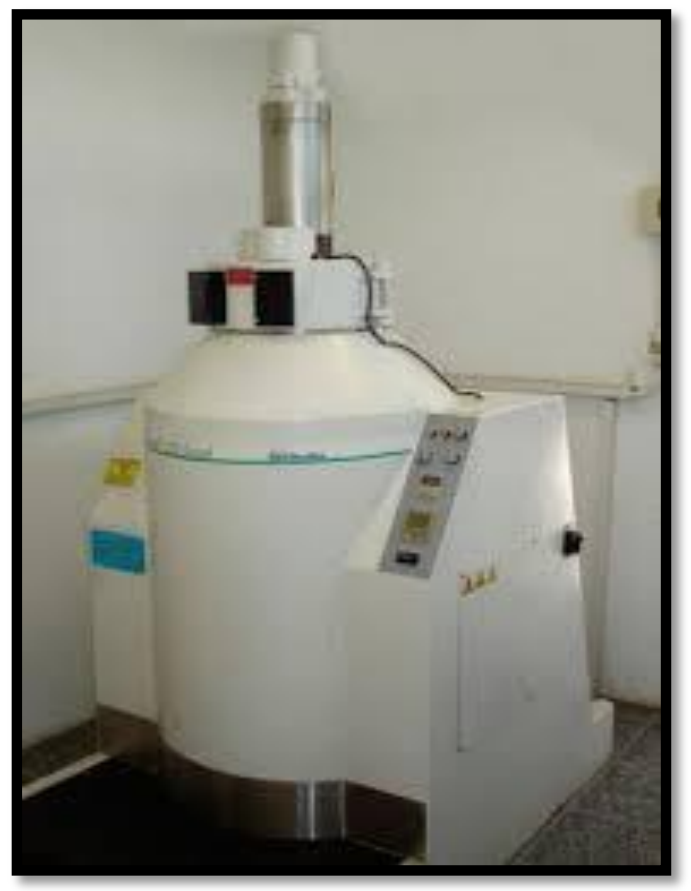

FIGURA 13 - Irradiador de Cobalto-60 usado no experimento

\subsection{Avaliação das amostras}

Após a irradiação, as placas de petri foram acondicionadas em caixas plásticas separadamente de acordo com o tratamento e em seguida colocadas câmara climática (B.O.D.) com temperatura de $25 \pm 5^{\circ} \mathrm{C}$ e umidade relativa de $70 \pm 5 \%$.

Posteriormente as avaliações foram realizadas a cada 24 horas, por um período de 22 dias após a irradiação, contando-se o número de: ovos, fases jovens, adultos e mortalidade dos ácaros.

\subsection{Delineamento experimental e análises estatísticas}

Para as análises estatísticas foram utilizados modelos lineares generalizados (NELDER e WEDDERBURN, 1972) com distribuição do tipo quase-binomial e gaussiana para análise dos dados de proporções de mortalidade e duração em dias das fases de ovos e ninfas das três espécies de 
ácaros envolvidas no estudo. A verificação da qualidade do ajuste dos dados foi feita por meio do uso do gráfico meio-normal de probabilidades com envelope de simulação (HINDE e DEMÉTRIO, 1998). Quando houve diferença significativa entre os tratamentos, múltiplas comparações (teste de Tukey, $P<0,05)$ foram realizadas por meio da função glht do pacote multicomp com ajuste dos valores de $P$. Todas as análises foram realizadas utilizando-se 0 software estatístico "R", versão 2.15.1 (R DEVELOPMENT CORE TEAM, 2012). 


\section{RESULTADOS E DISCUSSÃO}

\subsection{Biologia dos ácaros}

\subsection{Estimativas da viabilidade e duração da fase de ovo}

A diminuição da viabilidade de ovos dos ácaros foi diretamente proporcional ao aumento das doses de radiação. Na duração da fase de ovos, os efeitos da radiação induziram um aumento no período em dias na maturação e diminuição da viabilidade dos ovos nas três espécies de ácaros.

Nos resultados obtidos para $T$. urticae, nas doses de radiação utilizadas diferiram significativamente do tratamento controle. Sendo que na dose de 100 Gy obteve-se a maior viabilidade de ovos e na de 400 Gy a menor.

No entanto, o efeito da radiação gama prolongou o tempo de eclosão dos ovos em 1,2 dias na dose de 100 Gy e 8,9 dias para 200 Gy em comparação ao tratamento controle. Já a dose de 100 Gy foi a que apresentou o melhor resultado de viabilidade entre os tratamentos com radiação gama, apesar de não diferir estatisticamente do tratamento controle.

A dose intermediária de 200 Gy foi a que apresentou a maior duração da fase de ovo e diferiu significativamente da dose de 100 Gy e do tratamento controle, nas doses de 300 e 400 Gy os efeitos da radiação gama foram mais acentuados e mesmo a fêmea adulta produzindo ovos, esses não se desenvolveram e apresentaram a partir de alguns dias uma mutação letal dominante, que impediu a eclosão de ninfas nessas doses apresentando uma letalidade de $100 \%$, como podemos observar na (TAB. 1). 
TABELA 1 - Médias ( \pm erro padrão) da viabilidade e duração da fase ovo de Tetranychus urticae expostos à radiação Gama nas diferentes doses (Gy) Temp.: $25 \pm 2{ }^{\circ} \mathrm{C}$; U.R.: $70 \pm 10 \%$.

\begin{tabular}{|c|c|c|}
\hline Dose (Gy) & Viabilidade $(\%)^{1}$ & Duração (dias) ${ }^{2}$ \\
\hline 100 & $64,4 \pm 1,8^{b}$ & $5,1 \pm 0,4^{b}$ \\
\hline 200 & $35,4 \pm 2,4$ & $12,8 \pm 0,9^{a}$ \\
\hline 300 & $33,6 \pm 4,8^{6}$ & $0,0 \pm 0,0$ \\
\hline 400 & $30,1 \pm 3,1$ & $0,0 \pm 0,0$ \\
\hline Controle & $78,9 \pm 3,8^{\mathrm{a}}$ & $3,9 \pm 0,3^{6}$ \\
\hline $\begin{array}{c}\mathrm{F} \\
\text { Valor de } p\end{array}$ & $\begin{array}{c}67,0 \\
<0,0001\end{array}$ & $\begin{array}{c}63,2 \\
<0,0001\end{array}$ \\
\hline
\end{tabular}

'Médias seguidas de letras distintas nas colunas indicam diferenças significativas entre os tratamentos (GLM com distribuição quase-binomial seguido por teste post hoc de Tukey, $\mathrm{p}<0,05) ;{ }^{2}$ Médias seguidas de letras distintas nas colunas indicam diferenças significativas entre os tratamentos (GLM com distribuição Gaussiana seguido por teste post hoc de Tukey, $\mathrm{p}<0,05$ ).

${ }^{3^{*}}$ Não incluído na análise estatística (Variância nula)

O ácaro vermelho $T$. desertorum apresentou uma porcentagem de viabilidade de ovos maior em relação à espécie $T$. urticae, porém o tratamento controle também diferenciou significativamente em relação aos demais tratamentos com doses de radiação.

A dose de 100 Gy foi a que causou menores danos nos ovos dessa espécie de acaro. Com relação ao a duração da fase do ovo as doses de $100 \mathrm{e}$ 200 Gy foram as que apresentaram os maiores valores e foram significativamente diferentes do tratamento controle.

Nas doses de 300 e 400 Gy os efeitos da radiação gama foram mais acentuados induzindo uma mutação letal dominante que impediu a eclosão de ninfas apresentando uma letalidade de 100\%, como podemos observar na (TAB. 2). 
TABELA 2 - Médias ( \pm erro padrão) da viabilidade e duração da fase ovo de Tetranychus desertorum expostos à radiação Gama nas diferentes doses (Gy)

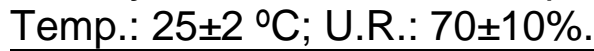

\begin{tabular}{|c|c|c|}
\hline Dose (Gy) & Viabilidade $(\%)^{1}$ & Duração (dias) ${ }^{2}$ \\
\hline 100 & $70,2 \pm 3,2^{b}$ & $7,5 \pm 1,1^{b}$ \\
\hline 200 & $56,8 \pm 2,5^{b}$ & $11,4 \pm 0,7^{a}$ \\
\hline 300 & $40,0 \pm 1,7^{6}$ & $0,0 \pm 0,0$ \\
\hline 400 & $35,4 \pm 4,0^{6}$ & $0,0 \pm 0,0$ \\
\hline Controle & $82,2 \pm 4,5^{a}$ & $3.98 \pm 0,5^{c}$ \\
\hline $\begin{array}{c}\mathrm{F} \\
\text { Valor de } p\end{array}$ & $\begin{array}{c}66,0 \\
<0,0001\end{array}$ & $\begin{array}{c}58,0 \\
<0,0001\end{array}$ \\
\hline
\end{tabular}

Médias seguidas de letras distintas nas colunas indicam diferenças significativas entre os tratamentos (GLM com distribuição quase-binomial seguido por teste post hoc de Tukey, $p<0,05) ;{ }^{2}$ Médias seguidas de letras distintas nas colunas indicam diferenças significativas entre os tratamentos (GLM com distribuição Gaussiana seguido por teste post hoc de Tukey, $\mathrm{p}<0,05$ ).

${ }^{3 *}$ Não incluído na análise estatística (Variância nula)

O acaro do café $O$. ilicis foi a espécie mais radiossensível, quando os ácaros adultos foram submetidos a radiação gama do Cobalto-60, pois a dose de 100 Gy apresentou uma porcentagem de viabilidade mais próxima ao tratamento controle em relação as demais espécies de ácaros desse estudo, a dose de 100 Gy não diferiu significativamente do tratamento controle, e a dose de $400 \mathrm{~Gy}$, as doses de 200 e 300 Gy foram as que apresentaram diferenças significativas em relação aos demais tratamentos.

Já na duração da fase de ovo 100 Gy diferiu significativamente do tratamento controle, essa dose também foi a única a gerar novos descendentes, pois nas doses superiores de 200, 300 e 400 Gy não apresentaram ninfas viáveis e, portanto sendo ovos estéreis (TAB. 3). 
TABELA 3 - Médias ( \pm erro padrão) da viabilidade e duração da fase ovo de Oligonychus ilicis expostos à radiação Gama nas diferentes doses (Gy) Temp.: 25 \pm 2 ㄷ); U.R.: $70 \pm 10 \%$.

\begin{tabular}{|c|c|c|}
\hline Dose (Gy) & Viabilidade $(\%)^{1}$ & Duração (dias) ${ }^{2}$ \\
\hline 100 & $73,4 \pm 2,3^{b}$ & $7,5 \pm 1,2^{\mathrm{a}}$ \\
\hline 200 & $56,0 \pm 1,5^{a}$ & $0,0 \pm 0,0^{-}$ \\
\hline 300 & $37,2 \pm 1,2^{c^{-}}$ & $0,0 \pm 0,0$ \\
\hline 400 & $53,4 \pm 0,6^{5}$ & $0,0 \pm 0,0$ \\
\hline Controle & $74,4 \pm 4,0^{6}$ & $3,9 \pm 0,5^{5}$ \\
\hline $\begin{array}{c}\mathrm{F} \\
\text { Valor de } p\end{array}$ & $\begin{array}{c}63,5 \\
<0,0001\end{array}$ & $\begin{array}{c}53,2 \\
<0,0001\end{array}$ \\
\hline
\end{tabular}

Médias seguidas de letras distintas nas colunas indicam diferenças significativas entre os tratamentos (GLM com distribuição quase-binomial seguido por teste post hoc de Tukey, $\mathrm{p}<0,05$ ); ${ }^{2}$ Médias seguidas de letras distintas nas colunas indicam diferenças significativas entre os tratamentos (GLM com distribuição Gaussiana seguido por teste post hoc de Tukey, $\mathrm{p}<0,05)$.

${ }^{3 *}$ Não incluído na análise estatística (Variância nula)

\subsection{Estimativas da viabilidade e duração da fase de ninfas}

A baixa viabilidade de ovos nos tratamentos com doses de radiação gama sobre essa fase da biologia dos ácaros refletiu em uma maior duração na fase de ovo e ninfa devido aos efeitos genéticos induzidos pela radiação gama.

Em T.urticae a porcentagem de viabilidade decresceu de acordo com o aumento das doses de radiação, a dose de $100 \mathrm{~Gy}$ foi a que apresentou os melhores resultados dos tratamentos com doses com radiação. Já a dose de 200 Gy foi a que apresentou a menor viabilidade de ovos. Na duração em dias para a fase de ninfas todas as doses de radiação apresentaram diferença significativa em relação ao tratamento controle, sendo que a dose de 200 Gy foi a que apresentou a maior duração e de 100 Gy a menor, nas doses de 300 e 400 Gy não houve eclosão dos ovos (TAB. 4). 
TABELA 4 - Médias ( \pm erro padrão) da viabilidade e duração da fase ninfas de Tetranychus urticae expostos à radiação Gama nas diferentes doses (Gy) Temp.:

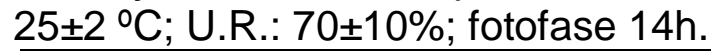

\begin{tabular}{ccc}
\hline Dose (Gy) & Viabilidade $(\%)^{1}$ & Duração (dias) ${ }^{2}$ \\
\hline 100 & $37,5 \pm 1,2^{b}$ & $5,6 \pm 0,3^{\mathrm{a}}$ \\
\hdashline 200 & $0,92 \pm 0,3^{\mathrm{c}}$ & $7,3 \pm 0,1^{\mathrm{a}}$ \\
\hline 300 & $0,0 \pm 0,0$ & $0,0 \pm 0,0$ \\
\hline 400 & $0,0 \pm 0,0$ & $0,0 \pm 0.0$ \\
\hline Controle & $76,6 \pm 1,2^{\mathrm{a}}$ & $4,0 \pm 0,3^{6}$ \\
\hline $\mathrm{F}$ & 68,1 & 54,7 \\
Valor de $p$ & $<0,0001$ & $<0,0001$ \\
\hline
\end{tabular}

Médias seguidas de letras distintas nas colunas indicam diferenças significativas entre os tratamentos (GLM com distribuição quase-binomial seguido por teste post hoc de Tukey, $p<0,05$ );

${ }^{2}$ Médias seguidas de letras distintas nas colunas indicam diferenças significativas entre os tratamentos (GLM com distribuição Gaussiana seguido por teste post hoc de Tukey, $p<0,05$ ).

${ }^{*}$ Não incluído na análise estatística (Variância nula)

Para a segunda espécie $T$. desertorum o tratamento controle apresentou diferença significativamente ao tratamento com irradiação na dose de 200 Gy sendo que esta dose foi a que apresentou uma maior proporção de ninfas viáveis.

Portanto esta espécie de acaro foi a qual apresentou a maior radioresistência aos efeitos da radiação gama. Já nas doses de 300 e 400 Gy a viabilidade das ninfas foi afetada drasticamente pelas radiações gama.

$\mathrm{Na}$ duração da fase de ninfas não houve diferenças significativas entre as porcentagens nas doses de 100,200 Gy e o tratamento controle, porém numericamente o tratamento controle foi a que apresentou menor tempo de duração na fase de ninfa (TAB.5). 
TABELA 5 - Médias ( \pm erro padrão) da viabilidade e duração da fase ninfas de Tetranychus desertorum expostos à radiação Gama nas diferentes doses (Gy) Temp.:

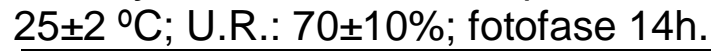

\begin{tabular}{ccc}
\hline Dose $($ Gy) & ${\text { Viabilidade }(\%)^{1}}^{1}$ & Duração (dias) $^{2}$ \\
\hline 100 & $16,7 \pm 7,8^{\mathrm{b}}$ & $6,4 \pm 0,3^{\mathrm{a}}$ \\
\hdashline 200 & $28,8 \pm 0,2^{\mathrm{b}}$ & $7,5 \pm 0,1^{\mathrm{a}}$ \\
\hline 300 & $0,0 \pm 0,0$ & $0.0 \pm 0,0$ \\
\hline 400 & $0,0 \pm 0,0$ & $0,0 \pm 0.0$ \\
\hline Controle & $79,3 \pm 0,2^{\mathrm{a}}$ & $5,96 \pm 0,7^{\mathrm{a}}$ \\
\hline $\mathrm{F}$ & 64,2 & 51,7 \\
Valor de $p$ & $<0,001$ & $<0,0001$ \\
\hline
\end{tabular}

Médias seguidas de letras distintas nas colunas indicam diferenças significativas entre os tratamentos (GLM com distribuição quase-binomial seguido por teste post hoc de Tukey, $p<0,05$ );

${ }^{2}$ Médias seguidas de letras distintas nas colunas indicam diferenças significativas entre os tratamentos

(GLM com distribuição Gaussiana seguido por teste post hoc de Tukey, $\mathrm{p}<0,05$ )

${ }^{3 *}$ Não incluído na análise estatística (Variância nula)

$\mathrm{Na}$ terceira espécie, o tetraniquídeo O.ilicis foi extremamente radiosensível e apresentou uma baixa viabilidade de ovos e os efeitos da radiação também influenciaram a viabilidade de ninfas, apenas a dose de 100 Gy apresentou viabilidade.

Portanto os dois parâmetros, a viabilidade e duração da fase de ninfa foram inferiores ao tratamento controle (TAB. 6). 
TABELA 6 - Médias ( \pm erro padrão) da viabilidade e duração da fase ninfas de Oligonychus ilicis expostos à radiação Gama nas diferentes doses (Gy) Temp.: $25 \pm 2$ 우 U.R.: $70 \pm 10 \%$; fotofase $14 \mathrm{~h}$.

\begin{tabular}{ccc}
\hline Dose (Gy) & Viabilidade $(\%)^{1}$ & Duração (dias) ${ }^{2}$ \\
\hline 100 & $22,4 \pm 4,5^{b}$ & $4.6 \pm 0,3^{b}$ \\
\hdashline 200 & $0,0 \pm 0,0$ & $0,0 \pm 0,0$ \\
\hline 300 & $0,0 \pm 0,0$ & $0,0 \pm 0,0$ \\
\hline 400 & $0,0 \pm 0,0$ & $0,0 \pm 0,0^{6}$ \\
\hline Controle & $73,4 \pm 1,4^{\mathrm{a}}$ & $3,6 \pm 0,2^{\mathrm{a}}$ \\
\hline $\mathrm{F}$ & 63,5 & 54,1 \\
Valor de $p$ & $<0,0001$ & $<0,001$ \\
\hline
\end{tabular}

Médias seguidas de letras distintas nas colunas indicam diferenças significativas entre os tratamentos (GLM com distribuição quase-binomial seguido por teste post hoc de Tukey, $p<0,05$ );

${ }^{2}$ Médias seguidas de letras distintas nas colunas indicam diferenças significativas entre os tratamentos

(GLM com distribuição Gaussiana seguido por teste post hoc de Tukey, $p<0,05$ ).

${ }^{*}$ Não incluído na análise estatística (Variância nula)

\subsection{Efeitos da Radiação Gama na Biologia dos ácaros}

De forma geral os ácaros das espécies: $T$. desertorum, $T$. urticae e Oligonychus ilicis apresentaram aspectos comportamentais semelhantes, havendo sempre uma diminuição na oviposição e um aumento na duração da fase de ovos proporcional ao aumento das doses de radiação gama do Cobalto-60.

Em relação à viabilidade das três espécies, foi visível que o aumento das doses de radiação é relacionado à baixa viabilidade dos ovos ovipositados pelos ácaros.

Fazendo-se uma comparação da viabilidade de ovos de àcaros irradiados x não irradiados das três espécies, temos uma média de 78,5\% de viabilidade no tratamento controle: $69,3 \%$ para a dose de 100 Gy: 49,4\% para a dose de 200 Gy. Para doses maiores que 200 Gy, a viabilidade de ovos de fêmeas irradiadas diminui para menos de $50 \%$.

Essa queda da viabilidade dos ovos reflete claramente na eclosão desses ovos, usando a mesma comparação acima de ácaros irradiados $X$ não irradiados a quantidade de ninfas viáveis de todos os ácaros do experimento é proporcional a perda de viabilidade desses ovos. 
Para eclosão de ninfas dos ovos irradiados das três espécies, os resultados foram bastante expressivos. No tratamento controle em média $79,3 \%$ dos ovos totais, foram viáveis e se transformaram em ninfas, na dose de 100 Gy $25,5 \%$ e na de 200 Gy com 14,8\%, menos de $50 \%$ desses ovos foram viáveis na dose de 100 e 20\% na dose de 200 Gy, sendo que a esterilidade em nosso estudo foi obtida a partir de 200 Gy em diante para os três ácaros.

IGNATOWICZ e BANASIK-SOLGALA (1999) também observaram a irradiação em ovos de três dias e notaram que ovos de um dia perderam sua eclodibilidade na dose de 100 Gy, enquanto que ovos de 2 a 3 dias não foram viáveis nas doses de 200 até 400 Gy.

Outros estudos como o de LESTER e PETRY (1995) em T. urticae mostraram que a dose de 350 Gy induziu a produção de ovos estéreis nesse ácaro.

MAJUMDER et al., (1996) afirmaram que mesmo doses de 5000Gy em ácaros Oligonychus biharensis Hirst não iria impedi-los de produzir ovos, embora doses de 300Gy possam causar a esterilização dos ovos, como em seu experimento.

A idade dos ovos foi outro importante fator observado, quanto mais velho é o ovo, geralmente menor a probabilidade de eclosão e conseqüentemente a viabilidade, no nosso experimento foi observando a idade média dos ovos das três espécies, ovos com 3-4 dias (49\%) foram viáveis na dose controle, 5-6 dias na dose de 100 Gy (35\%), mas já com uma diminuição na viabilidade e ovos com 7 dias em diante ocorreu esterilidade como na dose de 200 Gy em quase toda sua totalidade $(29,9 \%)$ e 300 Gy em sua totalidade para as três espécies(0,0\%).

Segundo SULAIMAN et al., (2004), ovos de Tetranychus Pierce McGregor eclodidos para um a dois dias de idade foi zero na dose de 150Gy, enquanto $41,3 \%$ são de três dias, 99,0\% com quatro dias de idade, os ovos antigos com mais de 4 dias, ainda eclodiram na dose de 600Gy. Os efeitos deterioativos da radiação ionizante nos ácaros refletem nas gerações subsequentes, como em adultos desenvolvidos a partir de ovos irradiados, na dose de 200Gy ou superior todos os ácaro que eclodiram eram fêmeas e estéril (não colocoram ovos). 
GOODWIN e WELLHAM (1990) estudaram os efeitos das doses a partir de 300 Gy sobre ácaros T.urticae e notaram que ovos eclodidos a partir de 24 horas já perdem eclodibilidade quando comparadas com doses controle.

Outros autores observaram resultados semelhantes em seus trabalhos (KHAN e ISLAM, 2006; HALLMAN e HELLMICH, 2009; MAHMOUD e BARTA, 2011; JANG et al., 2012). De acordo com IGNATOWICZ (1997), a sensibilidade de insetos e ácaros à irradiação varia de acordo com o estágio de desenvolvimento, e pode ocorrer em diferentes espécies e inclusive nas mesmas famílias, mas no geral, estágios juvenis têm maior sensibilidade devido à maior atividade de divisão celular nessa fase.

FOLLETT (2000 e 2006); BALESTRINO et al., (2010) observaram que a radiação ionizante é responsável pela quebra das ligações químicas do DNA e de outras biomoléculas como carboidratos, açucares, proteínas e lipídeos que causam um desarranjo celular prejudicando assim o seu funcionamento normal no organismo.

Para SAKURAI (2000) os efeitos da radiação gama influenciam também a alimentação dos insetos, pois causa um desarranjo nas células somáticas tais como o tecido epitelial presente no intestino dos insetos, o qual impossibilita que esse volte a se alimentar após a irradiação, morrendo por falta de alimentação.

CORK (1957); RIEMANN (1967); LE GALL e ARDAILLOU (2009); observaram que a irradiação causa o envelhecimento precoce do inseto e faz com que suas células tenham uma regeneração celular mais lenta, levando a maior oviposição de insetos e ácaros irradiados podem ser devido à falta de alimento e a reprodução é uma resposta imediata para a manutenção da espécie.

Hipótese que também é reforçada por algumas espécies de insetos e ácaros que pertencem a característica reprodutiva r-estrategista, o que faz com que essas espécies priorizem a reprodução como forma de gerar descendentes ao invés de estocar energia para sua própria sobrevivência (FORCE, 1975). 


\section{CONCLUSÕES}

- A dose de 200 Gy foi esterilizante para O.ilicis e 300 Gy para T.urticae e T.desertorum.

- As doses alcançadas nesse estudo são menores do que são exigidas hoje para o tratamento fitossanitário no mundo que é de 400 Gy.

- Além disso as doses esterilizantes desse estudo podem fazer parte de um conjunto de controle de ácaros dessa família para o manejo integrado de pragas (MIP). 


\section{REFERÊNCIAS BIBLIOGRÁFICAS}

ADIS, J. Taxonomical classification and biodiversity. (Ed). Amazonia Arachnida and Myriapoda. Sofia. Pensoft Publishers. 590p. 2001.

ANUÁRIO BRASILEIRO DA FRUTICULTURA. Ministério da Agricultura e do Abastecimento. Ed. Gazeta grupo de comunicações. 59:11-47. 2009.

ANUÁRIO BRASILEIRO DA FRUTICULTURA. Ministério da Agricultura e do Abastecimento. Ed. Gazeta grupo de comunicações, 136p. 2013.

ANVISA - AGÊNCIA NACIONAL DE VIGILÂNCIA SANITÁRIA. Disponível em:< http://portal.anvisa.gov.br/> Acesso em: 09 out. 2011.

ARTHUR, V. Controle de insetos pragas por radiações ionizantes. Biológico, São Paulo, 59:(1) 77-79, 1997.

ARTHUR, V. Uma visão crítica do uso de radiações gama como processo quarentenário para moscas-das-frutas. Tese de Livre-Docência, CENA. Universidade de São Paulo - USP, Piracicaba, SP. 67p. 1998.

ARTHUR, P. Emprego da radiação gama do cobalto-60 na desinfestação de alguns tipos de rações para alimentação de animais de pequeno porte. Dissertação de Mestrado - IPEN. Universidade de São Paulo - USP. São Paulo - SP. 56p. 2012.

ARTHUR, V.; ARTHUR, P. B.; GAVA, M. A.; FRANCO, S. S. H.; MACHI, A.R. Uso de técnicas nucleares em entomologia no Brasil. In: BUSOLI, A. C.; GRIGOLLI, J. F. J.; SOUZA, L. A.; KUBATA, M. M.; COSTA, E. N.; SANTOS, L. A. O.; NETTO, J. C.; VIANA, M. A. Tópicos em entomologia agrícola V. Jaboticabal: Gráfica e Editora Multipress. 13-25, 2012.

BALESTRINO, F.; MEDICI, A.; CANDINI, G.; CARRIERI, M.; MACCAGNANI, B.; CALVITTI, M.; MAINI, S.; BELLINI, R. Gamma ray dosimetry and mating capacity studies in the laboratory on Aedes albopictus males. Journal of Medical Entomology. 47:581-591. 2010.

BENTO JMS, Perdas por insetos na agricultura. Acão Ambiental. 4:19-21.1999.

BARROS, G.S.C.; SPOLADOR, H.F.S.; BACCHI, M.R.P. Supply and demand shocks and the growth of the brazilian agriculture. Revista Brasileira de Economia. 63:35-50. 2009.

BOARETTO, M. A. C.; BRANDÃO, A. L. S. Manejo Integrado de pragas. Apostila da Universidade Estadual do Sudoeste da Bahia, Vitória da Conquista, BA. 7p. 2000.

BOLLAND, H.R.; J. GUTIERREZ \& C.H.W. FLETCHMANN . World Catalogue of the spider mite family (Acari: Tetranychidae).Leiden, Koninklijke Brill NV, 408p. 1998. 
BOUNFOUR M, JEBBOUR F, WADJINNY J. Biological traits of invasive insect species harmful to Moroccan agriculture. In: Plant protection and plant health in Europe: introduction and spread of invasive species. BCPC Conference, Humbolt University (DE), 95-100. 2005.

CAMACHO, S.R. A barbárie moderna do agronegócio latifundiário exportador e suas implicações socioambientais. Revista Agrária. São Paulo, (13)169-195. 2010.

CAPALBO; D. M. F. Bacillus thuringiensis - este auxiliar ainda pouco conhecido, Ciência e tecnologia Informativo semana da Radiobras, 1998. Disponível em: http://www.radiobras.gov.br/ct/artigos/1998/artigo_260698.htm. Acesso em: 20 de Maio de 2012.

CARSON, R. Primavera silenciosa. 1 ed.- São Paulo: Gaia. 327p. 2010.

\section{CEPEA - CENTRO DE ESTUDOS AVANÇADOS EM ECONOMIA APLICADA CEPEA/ESALQ/USP. Disponível em:} www.cepea.esalq.usp.br/comunicacao/Cepea_ExportAgro_2011.doc. Acesso em: 30 de Out 2013.

COCKBURN, M.; MILLS, P.; ZHANG, X.; ZADNICK, J.; GOLDBERG, D.; RITZ, B. Prostate cancer and ambient pesticide exposure in agriculturally intensive areas in California. American Journal Epidemiology. 173:1280-1288. 2011.

COUTO, R. R.; SANTIAGO, A. J. Radioatividade e Irradiação de Alimentos. Revista Ciências Exatas e Naturais. 12:(2) 2010.

CORK, J.M. Gamma radiation and flour beetle. Radiation Research. 7:551-557. 1957.

DIEHL, J. F. Food irradiation: is an alternative to chemical preservations. Food Addition Contaminants. 9:409-416. 1992.

DIEHL, J. F. Assessment of wholesomeness of irradiated food: a review. Acta Alimentaria. 23:(2)195-214. 1994.

EMBRARAD - EMPRESA BRASILEIRA DE RADIAÇÃO. Disponível em: http://www.embrarad.com.br Acesso em: 03 nov. 2013.

ERMA - Environmental Risk Management Authority. Methyl bromide reassessment, Disponível em: http://www.epa.govt.nz/Documents/HRC08002Methyl-Bromide-decision.pdf, 2010, Acesso em: 05 Jun 2013)

EVANS, G.O. Principles of acarology. Wallingford, CAB International. 563. 1992.

FAO - FOOD AGRICULTURE ORGANIZATION, 2011. Disponível em: http://www.fao.org Acesso em: 23 out. 2013.

FARIA, J. T. Utilização da radiação gama como um processo quarentenário para - bicho furão Ecdytolopha aurantiana (Lima, 1927) (Lepidoptera, Fortricidae) em laranja pêra (Citrus sinensis) e o estudo de seus efeitos 
sobre a qualidade dos frutos. Tese de Doutorado. IPEN. Universidade de Sào Paulo - USP. São Paulo, SP. 75p. 1997.

FARKAS, J. Principios de la irradiación de alimentos. In: La Irradiación de alimentos en Latinoamérica, octubre 24-28, 1983, Lima, Perú. Proceedings.... Vienna. OIEA, p. 11-23.

FUNDAÇÃO OSVALDO CRUZ - FIOCRUZ. Radiação. Disponível em: http://www.fiocruz.br/biosseguranca/Bis/lab_virtual/radiacao.html. Acesso em 1 4 Set. 2013

FOLLETT, P.A.; LOWER, R. Irradiation to ensure quarantine security for Cryptophlebia spp. (Lepidoptera: Tortricidae) in sapindaceous fruits from Hawaii. Journal of Economic Entomology. 93:1848-1854. 2000.

FOLLETT P.A.; GRIFFIN, R. Irradiation as a phytosanitary treatment for fresh horticultural commodities: research and regulations. In: Sommers, $\mathrm{CH}$; Fan, $\mathrm{X}$ (Ed.) Food irradiation research and technology. Blackwell, Oxford. 143-168. 2006.

FLECHTMANN, C. H. W. Elementos de acarologia. São Paulo: Nobel. 344 p. 1975.

FLECHTMANN, C.H.W. Ácaros de importância agrícola. São Paulo: Nobel. 182p. 1979.

FORCE, D. C. Succession of R and K strategists in parasitoids. In: Price, P. W. (Ed.) Evolutionary Strategies of Insects and Mites. pp. 1 12-129. New York: Plenum. 22p. 1975.

GEMMILLA, A.; GUNIER, R. B.; BRADMAN, A.; ESKENAZI, B.; HARLEY, K. G. Residential Proximity to Methyl Bromide Use and Birth Outcomes in an Agricultural Population in California. Environmental Health Perspectives. 121:737-743. 2013.

GODFRAY, H.C.J., BEDDINGTON, J.R., CRUTE, J.I., HADDAD, L., LAWRENCE, D., MUIR, J.F., PRETTY, J., ROBINSON, S., THOMAS, S., TOULMIN, C., Food security: the challenge of feeding 9 billion people. Science. 327:812-818. 2010.

GOODWIN, S.,WELLHAM,T.M.Gamma irradiation for disinfestations of cut flowers infested by two spotted spider mite (Acarina:Tetranychidae). Journal of Economic Entomology. 83:1455-1458.1990.

HALLMAN, G. J. Ionizing Radiation Quarantine Treatment, United States Department of Agriculture, Agricultural Research Service $2301 \mathrm{~S}$. International Bldd., Weslaco, TX 78596, USA, 1998.

HALLMAN, G. J.; HELLMICH, R. L. Ionizing Radiation as a Phytosanitary Treatment Against European Corn Borer (Lepidoptera: Crambidae) in Ambient, Low Oxygen, and Cold Conditions. Journal of Economic Entomology. 102:64-68. 2009. 
HALLMAN, G. J.; THOMAS, D. B. lonizing radiation as a phytosanitary treatment against fruit flies (Diptera:Tephritidae): efficacy in naturally vs. artificially infested fruit. Journal of Economic Entomology. 103:1129-1134. 2010.

HALLMAN, G.J. Phytosanitary Applications of Irradiation. Comprehensive Reviews in Food Science and Food Safety. 10:143-151. 2011.

HALLMAN, G.J.; ARTHUR,V.; BLACKBURN, C.M.; PARKER, A.G. The case for a generic phytosanitary irradiation dose of 250 Gy for Lepidoptera eggs and larvae. Radiation Physics and Chemistry. 89:70-75. 2013.

HASAN, M.; KHAN, A.R. Control of stored product pests by irradiation. Integrated Pest Management Reviews. 3:15-29. 1998.

HEATHER, N.W.A; HALLMAN, G. J. Pest management and phytosanitary trade barriers. CABI, Wallingford, United Kingdom. 2008.

HINDE, J.; DEMÉTRIO, C.G.B. Over dispersion: model and estimation. Computational Statistics and Data Analysis, Elselvier. 27:151-170. 1998.

HINTON, T. G. Risks from exposure to radiation. In: NEWMAN, M. C. Fundamentals of Ecotoxicology. 2nd ed. CRC Press/ Lewis Publishers. Boca Raton, FL. 303304. 2003.

HOSSAIN, M.A.; HALLMAN G. J.; SHAKIL, A.K.; SAIDUL, M.I.M. Phytosanitary irradiation in South Asia. Journal of Entomology and Nematology. 3:44-53. 2011.

HU, M.Y.; LIU, X.Q., ZHOU, L.J.;.LO, X.M.; HOU, R.H.; WANG, Q.F. Irradiation as a quarantine treatment against citrus rust mite (Phyllocoptruta oleivora), In: Irradiation as a phytosanitary treatment of food and agricultural commodities. IAEA-TECDOC 1427 - International Atomic Energy Agency, Vienna, Austria.127-132. 2004.

IBGE, 2010. Instituto Brasileiro de Geografia e Estatıstica. Comentario. Disponível em:

http://www.ibge.gov.br/home/estatistica/indicadores/pib/pibvolval 201004comentarios.pdf. Acesso em: 09 de Setembro de 2013.

IBGE, 2011. Instituto Brasileiro de Geografia e Estatıstica. Notıcias. Disponível em: http://www.ibge.gov.br/ibgeteen/noticias/frameset.php. Acesso em: 13 de Jul de 2013.

INSTITUTO BRASILEIRO DE FRUTAS - IBRAF. Série Agronegócios. Cadeia produtiva de frutas. vol. 7. Jan/2007. Disponível em: http://www.ibraf.org.br/x files/Documentos/Cadeia Produtiva de Frutas S\%C 3\%A9rie Agroneg\%C3\%B3cios MAPA.pdf. Acesso em: 29 de Abr de 2013.

IGNATOWICZ, S. Post radiation mortality of the mold mite Tyrophagus putrescentiae (Acarida: Caridae) infesting agricultural commodities and used packagings. Annals of the Warsaw Agriculture University, Horticulture and Landscape Architecture.18:3-11. 1997. 
IGNATOWICZ, S.; BANASIK-SOLGALA, K. Gamma irradiation as a quarantine treatment for spider mites (Acarina: Tetranychidae) in horticultural products. In: Irradiation as a quarantine treatment of arthropod pests. IAEA-TECDOC1082, International Atomic Energy Agency, Vienna, Austria. 29-47. 1999.

JANG, E. B.; MCINNIS, D. O.; KURASHIMA, R.; WOODS, B.; SUCKLING, D. M. Irradiation of Adult Epiphyas postvittana (Lepidoptera: Tortricidae): Egg Sterility in Parental and F1 Generations. Journal of Economic Entomology. 105:5461. 2012.

JEPPSON, L.R.; KEIFER, H.H.; BAKER, E.W. Mites injurious to economic plants. Berkeley: University of California Press. 614p. 1975.

KIRITANI, K.; YAMAMURA, K. Exotic insects and their pathways for invasion. In: Invasive species: vectors and management strategies. (Ed.) Ruiz, G.M.; Carlton, J.T. Island, Washington, DC, 44-67. 2003.

KISHI, R.; ITOH, I.; ISHIZU, S.; HARABUCHI, I.; MIYAKE, H. Symptoms among workers with long-term exposure to methyl bromide. Annals of epidemiology. Sangyo lgaku 33:241-250,1991.

KHAN, H.S.; ISLAM, M. S. Efficacy of gamma radiation against housefly (musca domestica L.) reproduction and survival II. Adult treatment. Journal of biosciences. 14:.25-30. 2006.

LESTER, P.J.; PETRY, R.J. Gamma irradiation for after harvest disinfestations of diapausing twospotted spider mite (Acari: Tetranychidae). Journal of economic entomology. 88:1361-1364.1995.

LE GALL, J.Y.; Ardaillou, R. The biology of aging. Bulletin de l'Academie nationale de medecine.193:365-402. 2009.

LEVINE, J.M.; D'ANTONIO, C.M. Forecasting biological invasions with increasing internatinal trade. Conservation Biology. 17: 322-326. 2003.

LINHARES, M.Y.L, 1995. Pecuária, alimentos e sistemas agrários no Brasil (séculos XVII e XVIII). Archives du Centre Culturel. Calouste Gulbenkian 34:595-599. 1995.

MACHI. A.R.; GAVA, M.A.; ARTHUR, P.B.; ARTHUR.V. Utilização da radiação gama como um método alternativo de controle para Tetranychus urticae Koch (Acari: Tetranychidae). In: XXIV Congresso Brasileiro de Entomologia, Resumos. Curitiba - PR. 2012.

MAHMOUD, M.F.; BARTA, M. Effect of gamma radiation on the male sterility and other quality parameters of peach fruit fly, Bactrocera zonata (Saunders) (Diptera: Tephritidae) Horticultural Science. 38:54-62. 2011.

MAJUMDER, M.Z.R.; BHUIYA, A.D.; CHOWDHURY, N. Effects of radiation on mortality, fecundity and sterility of Oligonychus biharensis (Hirst) infesting 
common flower plants in Bangladesh. Bangladesh Journal of Zoology. 24:2532. 1996.

MENDONÇA, M.C; NASCIMENTO, A.S.; CALDAS, R.C.; FILHO, C.A.P. Efeito dot tratamento hidrotermico de mangas na mortalidade de Ceratitis capitata Wied.)(Díptera: Tephritidae) Anais Sociedade Entomológica Brasileira. 29:(1)139-145. 2000.

METCALF, R. Applied entomology in the twentyfirst century: needs and prospects. American Entomologist. 42:216-227. 1996.

METTLER JUNIOR, F.A.; UPTON, A.C. Medical effects of ionizing radiation. $2^{\text {nd }}$ (Ed.) Philadelphia, P.A. Saunders Company. 1995.

MINEIRO, J. L. C.; ARTHUR, V. Efeitos da radiação gama do Cobalto-60 em adultos de Tetranychus urticae Koch (Acari: Tetranychidae). In: Encontro Cientifico dos Pós-Graduandos no CENA/USP, Resumos. Piracicaba - SP. 2003. CDROM.

MINISTÉRIO DA AGRICULTURA E PECUÁRIA (MAPA). Tratamento fitossanitário e quarentenário. $2011 . \quad$ Disponível em: http://www.agricultura.gov.br/vegetal/exportacao/exigenciasfitossanitarias/trata mento-fitossanitario-e-quarentenario. Acesso em: 13 de Novembro de 2013.

MORAES, G.J.; FLECHTMANN, C.H.W. Manual de Acarologia. Acarologia básica e ácaros de plantas cultivadas no Brasil. Ribeirão Preto: Holos Editora, 288p. 2008.

NACHREINER, M.L.; SANTOS, R.R.P.; BOTEON, M. Janelas de mercado: a fruticultura brasileira no mercado internacional. In: Congresso da Sociedade Brasileira de Economia e Sociologia Rural. Anais. Juiz de Fora -MG. 2003. CD-ROM.

NELDER, J.A.; WEDDERBURN, R.W.M. Generalized linear models. Journal of the Royal Statistical Society: Series A: General Statistics, London. 135:370-384. 1972.

NELSON, D.W.M.; CROSSLAND, MR, SHINE, R. Indirect ecological impacts of an invasive toad on predator-prey interactions among native species. Biological Invasions. 12:3363-3369. 2010.

NORTON, R.A.; BONAMO, P.M.; GRIERSON, J.D.; SHEAR, W.A. Oribatid mite fossilis from a terrestrial Devonian deposit near Gilboa. Journal of Paleontology. 62:259-269.1988.

NORTON, R.A.; KETHLEY, J.B.; JOHNSTON D.E.; OCONNOR, B.M. Phylogenetic perspectives on genetic systems and reproductive modes of mites. In: WRENSCH, D.L.; EBBERT, M.A. (orgs.). Evolution and diversity of sex ratio in insects and mites. Chapman \& Hall Publications, New York. 8-99. 1993.

NOVAES, W. Só a quebradeira para ajudar o meio ambiente. O Estado de São Paulo On Line. 2008. 
OERKE, E.C. Crop losses to pests. Journal of Agricultural Science. 144:31-43. 2006.

OSOULI, S.H.; ZIAIE, F.; HADDAD IRANI NEJAD, K.; MOGHADDAM, M. Application of gamma irradiation on eggs, active and quiescence stages of Tetranychus urticae Koch as a quarantine treatment of cut flowers. Radiation Physics and Chemistry. 90:111-119. 2013.

PARTRIDGE, L. The new biology of ageing. Biological Sciences. 365:147-154. 2010.

PASSONI, A.C; NEVES, M.C.M.; RODRIGUES, B.B.; BOTEON, M. Análise dos principais entraves na exportação de frutas brasileiras. In: Congresso da Sociedade Brasileira de Economia e Sociologia Rural.. Anais. Fortaleza CE. 2006. CD-ROM.

PIMENTEL, D.; LACH, L.; ZUNIGA, R.; MORRISON, D.Environmental and economic costs associated with non-indigenous species in the United States. In: Pimentel $D(E d)$ Biological Invasions. Economic and Environmental costs of Alien Plants, Animal and Microbe Species. Boca Raton, USA: CRC Press. 285306. 2002.

R DEVELOPMENT CORE TEAM, R: A language and environment for statistical computing. 607 R Foundation for Statistical Computing, Vienna, Austria. 2012.

REIS P.R, COSTA JUNIOR A, LOBATO L.C.Blissus leucopterus (Say) (Hemiptera: Lygaeidae), nova praga das gramıneas introduzida no estado de Minas Gerais. Anais da Sociedade de Entomologia do Brasil. 5:241-242. 1976.

RIEMANN, J.G., FLINT, H.M. Irradiation effects on midgut and testes of the adult boll weevil, Anthonomus grandis, determined by histological and shielding studies, Annals of the Entomological Society of America. 60:298-308.1967.

RODRIGUES, C.M.A. Pesquisa agropecuária no período do pós-guerra. Tecnologias e Pesquisas agropecuárias. 4:205-254.1987.

SEAB - Secretaria de Estado da Agricultura e do Abastecimento DERAL Departamento de Economia Rural. Fruticultura - Análise da Conjuntura Agropecuária. Disponível em: http://www.agricultura.pr.gov.br/arquivos/File/deral/Prognosticos/fruticultura 20 12 13.pdf. Acesso em: 20 de Outubro de 2013.

SILVA, W.D.; ARTHUR,V.; MASTRANGELO, T. Response of oriental fruit moth, Grapholita molesta (Busck) (Lepidoptera:Tortricidae),eggs to gamma radiation. Radiation Physics and Chemistry. 79:1063-1066. 2010.

SAKURAI, H. Eradication of weevil by sterile-insect release method (4): physiology of reproduction in sterilized insects. Shokubutsu Boueki. 54:466- 468. 2000.

SATO, M. E. Ácaros predadores. In: BATISTA FILHO, A. Controle biológico de insetos e ácaros. São Paulo: Instituto Biológico.77-85. 2006. 
SALVO FILHO, A. Notas sobre o tratamento fitossanitário em citros. Laranja, Cordeirópolis. 18:(1)155-163. 1997.

SULAIMAN, H., OSMAN, M.S., OTHMAN, Z., ISMAIL, M.R. Development of irradiation as a quarantine treatment of mites on cut foliage and ornamentals. In: Irradiation as a Phytosanitary Treatment of Food and Agricultural Commodities. IAEA-TECDOC.1427. International Atomic Energy Agency, Vienna, Austria. 133-141.2004.

SANTOS R, Analise critica da interpretacao neoclassica do processo de modernizacao da agricultura brasileira. Revista de Economia Política. 8:131148. 1988.

THE GLOBAL COMPETITIVENESS REPORT 2011-2012. World economic forum. Disponível em: http://www3.weforum.org/docs/WEF GCR Report 2011-12.pdf. Acesso em: 09 nov 2013.

UNEP - United Nations Environment Programme. 2006. Handbook for the Montreal protocol on substances that deplete the ozone layer, 7th ed. $<$ http://ozone.unep.org/Publications/MP Handbook/Section 1.1 The Montreal Protocol/>.

USDA, 2011 - U. S. Department of Agriculture. Production, Supply and. Disponível em: http://www.fas.usda.gov/psdonline. Acesso em: 20 Set 2013.

USEPA - U. S. Environment Protection Agengy. Ionizing Radiation - Fact Book. Office of radiation and indoor air. EPA-402-F-06-061. 22p. 2007.

USEPA - U.S. Environmental Protection Agency. Protection of Stratospheric Ozone: The 2013 Critical Use Exemption from the Phaseout of Methyl Bromide. Fed Reg 77(241):74435-74449. Disponível em: http://www.gpo.gov/fdsys/pkg/FR2012-12-14/pdf/2012-30225.pdf. Acesso em: 21 fev 2013.

VITTI, A. Análise da competitividade das exportações brasileiras de frutas selecionadas no mercado internacional. 2009. Dissertação (Mestrado) Universidade de São Paulo, São Paulo.

WAQUIL, J. M. Manejo integrado de pragas:revisão histórica e perspectivas Embrapa Milho e Sorgo, Sete Lagoas, MG, s/d.

WESTPHAL, M.I.; BROWNE, M.; MACKINNON, K.; NOBLE, I. The link between international trade and the global distribution of invasive alien species. Biological Invasions. 10: 391-398. 2008.

WOODROW, J.E.; KRIEGER, R.I. Assessing exposure to agricultural fumigants in outdoor and indoor air environments. In: Assessing Exposures and Reducing Risks to People from the Use of Pesticides (Krieger Rl, ed). Washington, DC:American Chemical Society, 70-86. 2007.

YANINEK, J.S.; MORAES, G.J. DE. Mites in biological and integrated control of pests in agriculture, p.133- 149. In Dusbabek, F.; Bukva, V. (Eds.), Modern 
Acarology, Academia, Prague and SPB Academic Publishing bv, The Hague, 1:680p. 1991.

WIENDL, F. M. Irradiação de alimentos. Biológico. 59:(1)75-76. 1997. 